\title{
$\beta$-RA Targets Mitochondrial Metabolism and Adipogenesis, Leading to Therapeutic Benefits against CoQ Deficiency and Age-Related Overweight
}

\author{
Agustín Hidalgo-Gutiérrez ${ }^{1,2} \mathbb{D}$, Eliana Barriocanal-Casado ${ }^{1,2,+}{ }^{\dagger}$, María Elena Díaz-Casado ${ }^{1,2,+}$, \\ Pilar González-García ${ }^{1,2,+}$ (D), Riccardo Zenezini Chiozzi ${ }^{3,4}$, Darío Acuña-Castroviejo ${ }^{1,2,5}$ (D) \\ and Luis Carlos López 1,2,5,*(D)
}

check for updates

Citation: Hidalgo-Gutiérrez, A.; Barriocanal-Casado, E.;

Díaz-Casado, M.E.;

González-García, P.; Zenezini

Chiozzi, R.; Acuña-Castroviejo, D.;

López, L.C. $\beta$-RA Targets

Mitochondrial Metabolism and Adipogenesis, Leading to Therapeutic Benefits against CoQ Deficiency and

Age-Related Overweight.

Biomedicines 2021, 9, 1457. https://

doi.org/10.3390/biomedicines9101457

Academic Editor: Daniel L. Galvan

Received: 14 September 2021

Accepted: 9 October 2021

Published: 13 October 2021

Publisher's Note: MDPI stays neutral with regard to jurisdictional claims in published maps and institutional affiliations.

Copyright: (c) 2021 by the authors. Licensee MDPI, Basel, Switzerland. This article is an open access article distributed under the terms and conditions of the Creative Commons Attribution (CC BY) license (https:/ / creativecommons.org/licenses/by/ $4.0 /)$.
1 Departamento de Fisiología, Facultad de Medicina, Universidad de Granada, 18016 Granada, Spain; ahg@ugr.es (A.H.-G.); elianabc@ugr.es (E.B.-C.); elenadiaz@ugr.es (M.E.D.-C.); pgonzalez@ugr.es (P.G.-G.); dacuna@ugr.es (D.A.-C.)

2 Centro de Investigación Biomédica, Instituto de Biotecnología, Universidad de Granada, 18016 Granada, Spain

3 Biomolecular Mass Spectrometry and Proteomics, Bijvoet Center for Biomolecular Research, Utrecht Institute for Pharmaceutical Sciences, University of Utrecht, Padualaan 8, 3584 CH Utrecht, The Netherlands; r.zenezinichiozzi@uu.nl

4 Netherlands Proteomics Centre, Padualaan 8, 3584 CH Utrecht, The Netherlands

5 Centro de Investigación Biomédica en Red de Fragilidad y Envejecimiento Saludable (CIBERFES), 18016 Granada, Spain

* Correspondence: luisca@ugr.es

+ These authors contributed equally to this work.

Abstract: Primary mitochondrial diseases are caused by mutations in mitochondrial or nuclear genes, leading to the abnormal function of specific mitochondrial pathways. Mitochondrial dysfunction is also a secondary event in more common pathophysiological conditions, such as obesity and metabolic syndrome. In both cases, the improvement and management of mitochondrial homeostasis remain challenging. Here, we show that beta-resorcylic acid ( $\beta-R A)$, which is a natural phenolic compound, competed in vivo with 4-hydroxybenzoic acid, which is the natural precursor of coenzyme Q biosynthesis. This led to a decrease in demethoxyubiquinone, which is an intermediate metabolite of CoQ biosynthesis that is abnormally accumulated in $\operatorname{Coq} 9^{R 239 X}$ mice. As a consequence, $\beta$-RA rescued the phenotype of $\operatorname{Coq} 9^{R 239 X}$ mice, which is a model of primary mitochondrial encephalopathy. Moreover, we observed that long-term treatment with $\beta$-RA also reduced the size and content of the white adipose tissue (WAT) that is normally accumulated during aging in wild-type mice, leading to the prevention of hepatic steatosis and an increase in survival at the elderly stage of life. The reduction in WAT content was due to a decrease in adipogenesis, an adaptation of the mitochondrial proteome in the kidneys, and stimulation of glycolysis and acetyl-CoA metabolism. Therefore, our results demonstrate that $\beta$-RA acted through different cellular mechanisms, with effects on mitochondrial metabolism; as such, it may be used for the treatment of primary coenzyme $Q$ deficiency, overweight, and hepatic steatosis.

Keywords: mitochondrial disease; encephalopathy; astrogliosis; spongiosis; obesity; white adipose tissue; mitochondrial proteome; 3T3-L1; mouse model; hepatic steatosis

\section{Introduction}

Mitochondria are the primary sites of cellular energy production and also have a broad range of metabolic functions. Thus, mitochondrial dysfunction can produce farranging, varied, and severe consequences. Mitochondrial dysfunction can be directly caused by mutations in mitochondrial DNA or mutations in nuclear genes that encode mitochondrial proteins, leading to primary mitochondrial diseases. Aside from direct 
causes, mitochondrial dysfunction can also occur as a secondary event in more common diseases, such as neurodegenerative diseases, obesity, or metabolic syndrome.

One particular case of mitochondrial disease is coenzyme Q10 $\left(\mathrm{CoQ}_{10}\right)$ deficiency syndrome, which can be primarily caused by mutations in genes that encode proteins that are involved in the $\mathrm{CoQ}_{10}$ biosynthetic pathway (primary $\mathrm{CoQ}_{10}$ deficiency). Primary $\mathrm{CoQ}_{10}$ deficiency presents heterogeneous clinical phenotypes depending on the specific mutation in the CoQ biosynthesis pathway [1,2]. Furthermore, especially given the variety of functions of CoQ, multiple pathomechanisms are induced by low levels of CoQ, including declined bioenergetics [1,3-6], increased oxidative stress [3,4,7,8], disrupted sulfide metabolism $[9,10]$, and defective de novo pyrimidine biosynthesis [11].

$\mathrm{CoQ}_{10}$ deficiency can also be induced as a secondary effect of certain drugs [12] and triggered indirectly by other diseases, including multifactorial diseases and disorders that are caused by mutations in genes that are not related to the $\mathrm{CoQ}_{10}$ biosynthesis pathways [13-16]. Metabolic syndrome is a multifactorial disease with secondary mitochondrial dysfunction. The white adipose tissue (WAT) and skeletal muscle from patients and mice with insulin resistance, which is a characteristic that is usually associated with metabolic syndrome, show decreased levels of the CoQ biosynthetic proteins COQ7 and COQ9, leading to reduced CoQ levels in the mitochondria [17].

In experimental cases of $\mathrm{CoQ}_{10}$ deficiency, the levels of $\mathrm{CoQ}_{10}$ in blood, cells, and tissues could be increased by exogenous $\mathrm{CoQ}_{10}$ supplementation. However, $\mathrm{CoQ}_{10}$ has very low absorption and bioavailability when it is orally administrated, and a very low proportion of this exogenous $\mathrm{CoQ}_{10}$ can reach the mitochondria of the cells in most tissues $[18,19]$. Thus, hydroxybenzoic acid derivatives (HBAs) were proposed as an alternative strategy to attenuate $\mathrm{CoQ}_{10}$ deficiency since they were shown to modulate the endogenous CoQ biosynthetic pathway [20]. HBAs constitute a group of natural phenolic compounds that are present in plants with a general structure of the C6-C1 type that is derived from benzoic acid. Variable positioning of hydroxyl and methoxy groups on the aromatic ring produce several different compounds, such as 2-hydroxybenzoic acid (or salicylic acid), 4-hydroxybenzoic acid (4-HB), 2,4-dihydroxybenzoic acid (2,4-diHB, or $\beta$-resorcylic acid $(\beta-\mathrm{RA})$ ), and 4-hydroxy-3-methoxybenzoic acid (or vanillic acid (VA)). Interestingly, $\beta$-RA has a hydroxyl group that is incorporated into the benzoic ring during CoQ biosynthesis. This hydroxylation step is catalyzed by COQ7, which uses demethoxyubiquinone (DMQ) as a substrate and requires the COQ9 protein for its normal function and stability [6]. As a consequence, the administration of high doses of $\beta$-RA bypasses the defects in the COQ7 reaction, leading to a dramatic increase in the survival of Coq7 conditional knockout mice and the Coq $9^{R 239 X}$ mice due to increased levels of CoQ and/or to decreased levels of DMQ in the kidneys, heart, skeletal muscle and intestine [21-23]. In Coq9 $9^{R 239 X}$ mice, which is a model of mitochondrial encephalopathy due to the accumulation of DMQ and the reduced levels of $\mathrm{CoQ}$, these biochemical changes resulted in significant improvements in encephalopathic features, such as astrogliosis and spongiosis [22]. Similarly, supplementation with high doses of $\beta$-RA to podocyte-specific Coq6 or Adck4 (Coq8b) knockout mice prevented renal dysfunction and increased survival, although the effect of $\beta$-RA on CoQ metabolism in these mouse models was not reported and, therefore, the therapeutic mechanisms of these cases are unknown [24,25]. Additionally, Wang and colleagues reported that $\beta$-RA decreased the body weight of wild-type mice and increased survival in animals at the middle-age and elderly stages of life, but the mechanisms behind these observations remain to be elucidated. Consequently, these results in the Coq6 and Adck 4 mouse models and in wild-type mice suggest that $\beta$-RA may work through additional unidentified mechanisms.

Here, we evaluated whether a lower dose of $\beta-R A$, which may increase its translational potentiality, leads to therapeutic outcomes in the encephalopathic $\operatorname{Coq} 9^{R 239 X}$ mice and whether that effect is mainly due to $\beta$-RA interference in CoQ metabolism. Additionally, we tested whether $\beta$-RA could be a useful agent to treat the fat accumulation that is linked to aging. 


\section{Materials and Methods}

\subsection{Animals and Treatments}

$\operatorname{Coq}^{+/+}$and $\operatorname{Coq} 9^{R 239 X}$ mice were used in the study, both of which harbored a mix of C57BL/6N and C57BL/6J genetic backgrounds. The Coq9 ${ }^{R 239 X}$ mouse model (MGI: $5473628)$ was previously generated and characterized $[1,6,10]$. All animal manipulations were performed according to a protocol that was approved by the Institutional Animal Care and Use Committee of the University of Granada (procedures numbers 18/02/2019/016 18 February 2019 and 16/09/2019/153 16 September 2019) and were in accordance with the European Convention for the Protection of Vertebrate Animals Used for Experimental and Other Scientific Purposes (CETS \#123) and the Spanish law (R.D. 53/2013). Mice were housed in the Animal Facility of the University of Granada under an SPF zone with lights on at 7:00 AM and off at 7:00 PM. Mice had unlimited access to water and rodent chow $\left(\mathrm{SAFE}^{\circledR} 150\right.$, which provided $21,12.6$ and $66.4 \%$ of energy from proteins, lipids, and nitrogen-free extracts, respectively). Unless stated otherwise, the analytical experiments were completed on animals at 3 or 18 months of age.

$\beta$-Resorcylic acid ( $\beta$-RA) (Merck Life Science S.L.U, Madrid, Spain) was given to the mice in the chow at a concentration of $0.33 \%(w / w)$. For some experiments, a concentration of $1 \%(w / w) \beta-R A$ was used for two months [22]. A mix of $\beta-\mathrm{RA}$ and $4-\mathrm{HB}$ (at a concentration of $0.5 \%$ of each one) was also provided in the chow for particular experiments. Mice began receiving the assigned treatments at 1 month of age, and the analyses were performed at the age indicated for each case. Animals were randomly assigned to experimental groups. Data were randomly collected and processed.

The body weights were recorded once a month. To weigh the skeletal muscle, mice were sacrificed at 18 months of age and the gastrocnemius and vastus lateralis were dissected and weighed on a laboratory scale. To weigh the WAT, mice were sacrificed at 18 months of age, and the epididymal, mesenteric, and inguinal WATs were dissected and weighed on a laboratory scale.

The motor coordination was assessed at different months of age using the rotarod test by recording the length of time that mice could remain on the rod ("latency to fall"), rotating at a rate of $4 \mathrm{rpm}$, accelerating to $40 \mathrm{rpm}$ in $300 \mathrm{~s}$. Muscle strength was assessed using a computerized grip strength meter (Model 47200, Ugo-Basile, Varese, Italy). The experimenter held the mouse gently by the base of the tail, allowing the animal to grab the metal bar with the forelimbs before being gently pulled until it released its grip. The peak force of each measurement was automatically recorded by the device and expressed in grams $(\mathrm{g})$. The hindlimb grip strength of each mouse was measured in duplicate with at least 1 min between measurements [1].

\subsection{Cell Culture and Cell Assays}

3T3-L1 preadipocytes (ECACC \#: 86052701; lot CB 2618) were obtained from the cell bank of the University of Granada and maintained in DMEM containing 10\% fetal calf serum (FCS) in a humidified atmosphere of $5 \% \mathrm{CO}_{2}$ at $37^{\circ} \mathrm{C}$. The differentiation of the preadipocytes was induced 2 days post-confluence (day 0 ) following the manufacturer's instructions (DIF001-1KT; Merck Life Science S.L.U, Madrid, Spain)) via the addition of $0.5 \mathrm{mM}$ 3-isobutyl-1-methylxanthine (IBMX), $1 \mu \mathrm{M}$ dexamethasone, and $10 \mu \mathrm{g} / \mathrm{mL}$ insulin (multiple daily insulin (MDI)) for 2 days. Subsequently, the culture medium was changed to DMEM and $10 \%$ fetal bovine serum (FBS) containing insulin. After 2 days, the medium was replaced with DMEM and 10\% FBS, and the cells were incubated for a further 2 days until the cells were harvested to be used in the experiments described below.

C2C12 myocytes (ECACC \#: 91031101; lot 08F021) were obtained from the cell bank at the University of Granada and maintained in DMEM containing 10\% FBS in a humidified atmosphere of $5 \% \mathrm{CO}_{2}$ at $37{ }^{\circ} \mathrm{C}$. The differentiation of the preadipocytes was induced 1-day post-confluence (day 0) by changing to a $1 \%$ FBS medium. Subsequently, the culture medium was changed to DMEM and $1 \%$ FBS. The medium was changed every other day and the cells were harvested to be used in the experiments described below. 
In both cell types, namely, 3T3-L1 and C2C12, each assay was carried out in one of three experimental conditions: proliferative, differentiative, or proliferative + differentiative. Proliferative conditions were developed in both types of cells after cell splitting, and cells were collected upon reaching the confluency at day 7. Differentiative conditions were initiated in both cell types when the cells reached confluency. In 3T3-L1 cells, the differentiation was induced with the differentiation medium described above. In the $\mathrm{C} 2 \mathrm{C} 12$ cells, differentiation was induced in a medium with $1 \% \mathrm{FBS}$, as described above. The cells were collected on day 7. Proliferative + differentiative conditions combined both procedures in the same experiment. $\beta$-RA was added at a final concentration of $1 \mathrm{mM}$ every other day in each experimental condition.

To visualize the lipid droplets, the 3T3-L1 cells were fixed in formalin and stained with Oil Red solution on days 2, 4, and 6 in both the proliferative and proliferative + differentiative conditions.

Cell viability and proliferation were quantified on day 7 using a Vybrant MTT Cell Proliferation Assay Kit according to the manufacturer's instructions (Thermofisher, Madrid, Spain). Absorbance was measured at $450 \mathrm{~nm}$ on a microplate reader (Powerwave $\times 340$ spectrophotometer; Biotek, Winooski, VT, USA).

\subsection{Histology and Immunohistochemistry}

Tissues were fixed in formalin and embedded in paraffin. Multiple sections $(4 \mu \mathrm{m}$ thickness) were deparaffinized with xylene and stained with hematoxylin and eosin (H\&E) (Merck Life Science S.L.U, Madrid, Spain), Masson's trichrome, or Oil Red (Merck Life Science S.L.U, Madrid, Spain). Immunohistochemistry was carried out on the same sections using the following primary antibodies: glial fibrillary acidic protein or anti-GFAP (glial fibrillary acidic protein) (MAB360; Millipore, Madrid, Spain). The Dako Animal Research Kit for mouse primary antibodies (Dako, Agilent Technologies, Madrid, Spain) was used for the qualitative identification of antigens by light microscopy. Sections were examined at 40-400 magnifications with a Nikon Eclipse Ni-U microscope (Werfen, Madrid, Spain), and the images were scanned under equal light conditions with the NIS-Elements Br computer software (Werfen, Madrid, Spain).

\subsection{Plasma and Urine Analysis}

Blood samples were collected in $\mathrm{K}_{3}$-ethylenediaminetetraacetic acid (EDTA) tubes (Kima, VWR, Barcelona, Spain) using a goldenrod lancet and the submandibular vein of each mouse as a puncture site. The plasma was extracted from blood samples via centrifugation at $4500 \times \mathrm{g}$ for $10 \mathrm{~min}$ at $4{ }^{\circ} \mathrm{C}$. Biochemical analyses of the urine and plasma were developed in a biochemical analyzer Bs-200 (Shenzhen Mindray Bio-Medical Electronics Co., Ltd., Shenzhen, China) using reagents from Spinreact.

The NEFAS concentration was quantified using the Free Fatty Acid Quantitation Kit (MAK044) according to the technical bulletin (Merck Life Science S.L.U, Madrid, Spain). The results were expressed in nanograms per microliter.

The insulin concentration was quantified using the Mouse INS ELISA Kit (EM0260) according to the manufacturer's instructions (FineTest, Labclinics, Barcelona, Spain). The results were expressed in picograms per milliliter.

The Glucagon concentration was quantified using the Mouse GC ELISA Kit (EM0562) according to the manufacturer's instructions (FineTest, Labclinics, Barcelona, Spain).The results were expressed in picograms per milliliter.

\subsection{Mitochondrial Proteomics Analysis}

Both the $\operatorname{Coq} 9^{+/+}$mice and $\operatorname{Coq} 9^{+/+}$mice that were given the $1 \% \beta$-RA supplementation were sacrificed, and the kidneys were removed and washed in a saline buffer. The tissues were chopped with scissors in 3 mL HEENK (10 mM 4-(2-hydroxyethyl)1-piperazineethanesulfonic acid (HEPES), $1 \mathrm{mM}$ EDTA, $1 \mathrm{mM}$ ethylene glycol-bis( $\beta$ aminoethyl ether)- $\mathrm{N}, \mathrm{N}, \mathrm{N}^{\prime}, \mathrm{N}^{\prime}$-tetraacetic acid (EGTA), $10 \mathrm{mM} \mathrm{NaCl}, 150 \mathrm{mM} \mathrm{KCl}, \mathrm{pH}$ 
7.1, 300 mOsm/L) (Merck Life Science S.L.U, Madrid, Spain) containing $1 \mathrm{mM}$ phenylmethanesulfonyl fluoride (PMFS) (Merck Life Science S.L.U, Madrid, Spain) (from $0.1 \mathrm{M}$ stock in isopropanol) and $1 \times$ protease inhibitor cocktail (Pierce). The tissues were homogenized with a $3 \mathrm{~mL}$ Dounce homogenizer (5 passes of a tight-fitting Teflon piston). Each obtained homogenate was rapidly subjected to standard differential centrifugation methods until a mitochondrial pellet was obtained, as previously described [26]. Briefly, the homogenate was centrifuged at $600 \times g$ for $5 \mathrm{~min}$ at $4{ }^{\circ} \mathrm{C}$ (twice), and the resultant supernatant was centrifuged at $9000 \times g$ for $5 \min$ at $4{ }^{\circ} \mathrm{C}$. The final pellet, corresponding to a crude mitochondrial fraction, was resuspended in $500 \mu \mathrm{L}$ of HEENK medium without PMSF or protease inhibitor [26]. The protein concentration was determined (using Bradford dye, Bio-Rad, Madrid, Spain) and a Shimadzu spectrophotometer, resulting in approximately $3 \mathrm{mg}$ protein for renal mitochondria and $1.5 \mathrm{mg}$ for cerebral mitochondria. To verify the content of the mitochondrial fraction, complex IV activity was determined using optical absorption of the difference spectrum at $550 \mathrm{~nm}$, as previously described [10].

The purified mitochondria were spun down to remove the previous buffer, and lysis buffer (1\% sodium deoxycholate SDC in $100 \mathrm{mM}$ Tris at $\mathrm{pH} 8.5)$ was added to the pellets. The samples were boiled for $5 \mathrm{~min}$ at $99^{\circ} \mathrm{C}$ to denature all the proteins and then sonicated using microtip probe sonication (Hielscher UP100H Lab Homogenizer, Hielscher Ultrasonics $\mathrm{GmbH}$, Teltow, Germany) for 2 min with pulses of $1 \mathrm{~s}$ on and $1 \mathrm{~s}$ off at $80 \%$ amplitude. The protein concentration was estimated using a bicinchoninic acid assay (BCA) and $200 \mu \mathrm{g}$ were taken from each sample. Then, $10 \mathrm{mM}$ tris(2-carboxyethyl)phosphine and $40 \mathrm{mM}$ chloroacetamide (final concentration) at $56^{\circ} \mathrm{C}$ were added to each of these $200 \mu \mathrm{g}$ samples for $10 \mathrm{~min}$ to reduce and alkylate the disulfide bridges. After this step, samples were digested with LysC (FUJIFILM Wako Chemicals Europe GmbH, Neuss, Germany) in an enzyme/protein ratio of 1:100 (w/w) for $1 \mathrm{~h}$, followed by a trypsin digest (Promega, Leiden, The Netherlands) 1:50 (w/w) overnight. Protease activity was quenched with trifluoroacetic acid (TFA) to a final $\mathrm{pH}$ of $\sim 2$. Samples were then centrifuged at $5000 \times g$ for $10 \mathrm{~min}$ to eliminate the insoluble SDC, and loaded on an OASIS HLB (Waters Chromatography Europe, Etten-Leur, The Netherlands) 96-well plate. Samples were washed with $0.1 \%$ TFA, eluted with a 50/50 acetonitrile (ACN) and $0.1 \%$ TFA, dried using a SpeedVac (Eppendorf, Hamburg, Germany), and resuspended in $2 \%$ formic acid prior to the MS analysis. From each sample, $5 \mu \mathrm{g}$ were taken and pooled in order to be used for quality control for MS (1 QC was analyzed every 12 samples) and to be fractionated at a high $\mathrm{pH}$ for the match between runs.

All samples with the QC and 7 high-pH fractions were acquired using a UHPLC 1290 system (Agilent Technologies, Santa Clara, CA, USA) that was coupled online to a Q Exactive HF mass spectrometer (Thermo Scientific, Bremen, Germany). Peptides were first trapped (Dr. Maisch Reprosil C18, $3 \mu \mathrm{m}, 2 \mathrm{~cm} \times 100 \mu \mathrm{m}$ ) prior to separation on an analytical column (Agilent Poroshell EC-C18, $2.7 \mu \mathrm{m}, 50 \mathrm{~cm} \times 75 \mu \mathrm{m}$ ). Trapping was performed for $5 \mathrm{~min}$ in solvent $\mathrm{A}(0.1 \% \mathrm{v} / \mathrm{v}$ formic acid in water), and the gradient was as follows: $10-40 \%$ solvent B ( $0.1 \%$ v $/ v$ formic acid in $80 \%$ v/v ACN) over $95 \mathrm{~min}, 40-100 \%$ $\mathrm{B}$ over $2 \mathrm{~min}$, then the column was cleaned for $4 \mathrm{~min}$ and equilibrated for $10 \mathrm{~min}$ (flow was passively split to approximately $300 \mathrm{~nL} / \mathrm{min}$ ). The mass spectrometer was operated in a data-dependent mode. Full-scan MS spectra in the range of m/z 300-1600 Th were acquired in the Orbitrap at a resolution of 120,000 after accumulation to a target value of $3 \times 10^{6}$ with a maximum injection time of $120 \mathrm{~ms}$. The 15 most abundant ions were fragmented with a dynamic exclusion of $24 \mathrm{~s}$. HCD fragmentation spectra (MS/MS) were acquired in the Orbitrap at a resolution of 30,000 after accumulation to a target value of $1 \times 10^{5}$ with an isolation window of 1.4 Th and a maximum injection time of $54 \mathrm{~ms}$.

All raw files were analyzed with MaxQuant v1.6.10 software (Martinsried, Germany) [27] using the integrated Andromeda Search engine and searched against the mouse UniProt Reference Proteome (November 2019 release with 55,412 protein sequences) with common contaminants. Trypsin was specified as the enzyme, allowing up to two missed cleavages. Carbamidomethylation of cysteine was specified as fixed modification and 
protein N-terminal acetylation, oxidation of methionine, and deamidation of asparagine were considered variable modifications. We used all the automatic settings and activated the "match between runs" (time window of 0.7 min and alignment time window of $20 \mathrm{~min}$ ) and LFQ with standard parameters. The files generated by MaxQuant were opened in Perseus for the preliminary data analysis: the LFQ data were first transformed in $\log 2$, then the identifications that were present in at least $\mathrm{N}(3 / 5)$ biological replicates were kept for further analysis; missing values were then imputed using the standard settings of Perseus. Ingenuity pathway analysis (IPA) was used to identify the changes in metabolic canonical pathways and their z-score predictions [28].

\subsection{Sample Preparation and Western Blot Analysis in Tissues and Cells}

For the Western blot analyses, a glass Teflon homogenizer was used to homogenize the mouse kidney, liver, skeletal muscle, and WAT samples at $1100 \mathrm{rpm}$ in a T-PER ${ }^{\circledR}$ buffer (Thermo Scientific, Madrid, Spain) with a protease and phosphatase inhibitor cocktail (Pierce, Fisher Scientific, Madrid, Spain). Homogenates were sonicated and centrifuged at $1000 \times g$ for $5 \mathrm{~min}$ at $4^{\circ} \mathrm{C}$, and the resultant supernatants were used for the Western blot analysis. For the Western blot analyses of the cells, the pellets containing the cells were re-suspended in RIPA buffer with a protease inhibitor cocktail. About $30 \mu \mathrm{g}$ of protein from the sample extracts were electrophoresed in 12\% Mini-PROTEAN TGXTM precast gels (BioRad) using the electrophoresis system mini-PROTEAN Tetra Cell (Bio-Rad). Proteins were transferred onto PVDF $0.45 \mu \mathrm{m}$ membranes using a Trans-Blot Cell (Bio-Rad) and probed with target antibodies. Protein-antibody interactions were detected using peroxidaseconjugated horse anti-mouse, anti-rabbit, or anti-goat IgG antibodies and Amersham ECLTM Prime Western Blotting Detection Reagent (GE Healthcare, Buckinghamshire, UK). Band quantification was carried out using an Image Station 2000R (Kodak, Madrid, Spain) and Kodak 1D 3.6 software (Kodak, Madrid, Spain). Protein band intensity was normalized to VDAC1 for mitochondrial proteins and to GAPDH or $\beta$-actin for cytosolic proteins. The data were expressed in terms of the percent relative to wild-type mice or control cells.

The following primary antibodies were used: anti-ALDH1B1 (15560-1-AP, Proteintech, Manchester, UK), anti-GSK3B (22104-1-AP, Proteintech, Manchester, UK), anti-EHHADH (sc-393123, Santa Cruz, Heidelberg, Germany), anti-ACADM (ab110296, Abcam, Cambridge, UK), anti-SKP2 (15010-AP, Proteintech, Manchester, UK), anti-P27 (25614-1-AP, Proteintech, Manchester, UK), anti-Cyc A2 (18202-1-AP, Proteintech, Manchester, UK), anti- $\beta$-ACTIN (sc-47778, Santa Cruz, Heidelberg, Germany), anti-PPAR $\gamma$ (MA5-14889,

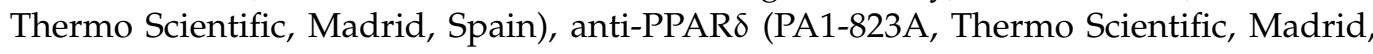
Spain), anti-AMPK (\#2532, Cell Signaling, Danvers, MA, USA), anti-P-AMPK (\#2531, Cell Signaling, Danvers, MA, USA), anti-ULK1 (\#8054, Cell Signaling, Danvers, MA, USA), anti-P-ULK1 (\#5869, Cell Signaling, Danvers, MA, USA), anti-ACC (\#3676, Cell Signaling, Danvers, MA, USA), and anti-P-ACC (\#11818, Cell Signaling, Danvers, MA, USA).

\subsection{Quantification of $\mathrm{Co}_{9}$ and $\mathrm{CoQ}_{10}$ Levels in Mice Tissues and 3T3-L1 Cells}

After the lipid extraction from homogenized tissues and cultured cells, $\mathrm{CoQ}_{9}$ and $\mathrm{CoQ}_{10}$ levels were determined via reversed-phase HPLC coupled to electrochemical detection, as previously described $[1,6]$. The results were expressed in nanograms of CoQ per milligram of protein.

\subsection{CoQ-Dependent Respiratory Chain Activities}

Coenzyme Q-dependent respiratory chain activities were measured in tissue samples of brain, kidney, skeletal muscle, and heart. Tissue samples were homogenized in a CPT medium (0.05 M Tris- $\mathrm{HCl}, 0.15 \mathrm{M} \mathrm{KCl}, \mathrm{pH} 7.5)$ at $1100 \mathrm{rpm}$ in a glass Teflon homogenizer. Homogenates were sonicated and centrifuged at $600 \times \mathrm{g}$ for $20 \mathrm{~min}$ at $4{ }^{\circ} \mathrm{C}$, and the obtained supernatants were used to measure the CoQ-dependent respiratory chain activities $(\mathrm{CI}+\mathrm{III}$ and CII + III), as previously described [22]. 


\subsection{Metabolic Assays in Tissues}

Phosphofructokinase enzyme activity was measured using a kit from Merck Life Science S.L.U. (Madrid, Spain) (Phosphofructokinase Activity Colorimetric Assay Kit MAK093) according to the manufacturer's instructions. The enzyme activity was expressed in micromoles per minute per milligram of protein.

Pyruvate kinase enzyme activity was measured using a kit from Merck Life Science S.L.U. (Madrid, Spain) (Pyruvate kinase Activity Colorimetric Assay Kit MAK072) according to the manufacturer's instructions. The enzyme activity was expressed in picomoles per minute per milligram of protein.

The G3P concentration was quantified using the Glycerol-3-Phosphate Assay Kit (MAK207) according to the technical bulletin (Merck Life Science S.L.U, Madrid, Spain). The concentration of G3P was expressed in nanograms per microgram of protein.

The BHB concentration was quantified using the Beta-Hydroxybutyrate Assay Kit (MAK041) according to the technical bulletin (Merck Life Science S.L.U, Madrid, Spain). The concentration of BHB was expressed in nanograms per microgram of protein.

\subsection{Mitochondrial Respiration}

Mitochondrial isolation from the brain and the kidneys was performed as previously described [22,29]. To isolate fresh mitochondria, mice were sacrificed and the organs were extracted rapidly and put on ice. Brain was homogenized $(1: 10, \mathrm{w} / \mathrm{v})$ in a respiration buffer $\mathrm{C}(0.32 \mathrm{M}$ sucrose, $1 \mathrm{mM}$ EDTA-K+, $10 \mathrm{mM}$ Tris- $\mathrm{HCl}, \mathrm{pH} 7.4)$ at $500 \mathrm{rpm}$ at $4{ }^{\circ} \mathrm{C}$ in a glass Teflon homogenizer. The homogenate was centrifuged at $13,000 \times \mathrm{g}$ for $3 \mathrm{~min}$ at $4{ }^{\circ} \mathrm{C}$. The supernatant (s1) was kept on ice and the pellet was re-suspended in $5 \mathrm{~mL}$ of buffer A and centrifuged at $13,000 \times g$ for $3 \mathrm{~min}$ at $4{ }^{\circ} \mathrm{C}$. The subsequent supernatant (s2) was combined with s1 and centrifuged at $21,200 \times \mathrm{g}$ for $10 \mathrm{~min}$ at $4{ }^{\circ} \mathrm{C}$. The mitochondrial pellet of this step was re-suspended in a $0.85 \mathrm{~mL}$ extraction buffer A containing $15 \%$ Percoll, poured into ultracentrifuge tubes containing a Percoll gradient formed by $1 \mathrm{~mL} 40 \%$ Percoll and $1 \mathrm{~mL}$ $23 \%$ Percoll in buffer $\mathrm{A}$, and centrifuged at $63,000 \times \mathrm{g}$ for $30 \mathrm{~min}$ at $4{ }^{\circ} \mathrm{C}$. Pure mitochondria, corresponding to a fraction between 23 and $40 \%$ Percoll, were collected and washed twice with $1 \mathrm{~mL}$ of buffer $\mathrm{A}$ at $10,300 \times \mathrm{g}$ for $10 \mathrm{~min}$ at $4{ }^{\circ} \mathrm{C}$. The mitochondrial pellets were suspended in MAS $1 \times$ medium. Kidney was homogenized $(1: 10, w / v)$ in a respiration buffer A ( $250 \mathrm{mM}$ sucrose, $0.5 \mathrm{mM} \mathrm{Na} \mathrm{E}_{2} \mathrm{EDTA}, 10 \mathrm{mM}$ Tris, and $1 \%$ free fatty acid albumin) at $800 \mathrm{rpm}$ in a glass Teflon homogenizer. Then, the homogenate was centrifuged at $500 \times g$ for $7 \mathrm{~min}$ at $4{ }^{\circ} \mathrm{C}$ and the supernatant was centrifuged at $7800 \times \mathrm{g}$ for $10 \mathrm{~min}$ at $4{ }^{\circ} \mathrm{C}$. The pellet was then resuspended in respiration buffer B ( $250 \mathrm{mM}$ sucrose, $0.5 \mathrm{mM}$ Na2EDTA, and $10 \mathrm{mM}$ Tris) and an aliquot was used for the protein determination. The remaining sample was then centrifuged at $6000 \times g$ for $10 \mathrm{~min}$ at $4{ }^{\circ} \mathrm{C}$. The pellet was resuspended in buffer $A$ and centrifuged again at $6000 \times g$ for $10 \mathrm{~min}$ at $4{ }^{\circ} \mathrm{C}$. The final crude mitochondrial pellet was re-suspended in MAS $1 \times$ medium [ $70 \mathrm{mM}$ sucrose, $220 \mathrm{mM}$ mannitol, $10 \mathrm{mM}$ $\mathrm{KH}_{2} \mathrm{PO}_{4}, 5 \mathrm{mM} \mathrm{MgCl} 2,2 \mathrm{mM}$ HEPES, $1 \mathrm{mM}$ EGTA and $0.2 \%$ (w/v) fatty acid-free BSA, $\mathrm{pH}$ 7.2, all from Merck Life Science S.L.U, Madrid, Spain].

Mitochondrial respiration was measured with an $\mathrm{XF}^{\mathrm{e} 24}$ Extracellular Flux Analyzer (Seahorse Bioscience, Agilent Technologies, Madrid, Spain) $[22,29,30]$. The mitochondria were first diluted in cold MAS $1 \times$ for plating ( $3.5 \mu \mathrm{g} /$ well in brain; $2 \mu \mathrm{g} /$ well in kidney). Next, $50 \mu \mathrm{L}$ of mitochondrial suspension was delivered to each well (except for background correction wells) while the plate was on ice. The plate was then centrifuged at $2000 \times g$ for $10 \mathrm{~min}$ at $4{ }^{\circ} \mathrm{C}$. After centrifugation, $450 \mu \mathrm{L}$ of MAS $1 \times+$ substrate $(10 \mathrm{mM}$ succinate, $2 \mathrm{mM}$ malate, $2 \mathrm{mM}$ glutamate, and $10 \mathrm{mM}$ pyruvate) was added to each well. Respiration by the mitochondria was sequentially measured in a coupled state with the substrate present (basal respiration or state 2) followed by state $3 \mathrm{o}$ (phosphorylating respiration, in the presence of ADP and substrates). State 4 (non-phosphorylating or resting respiration) was measured after the addition of oligomycin when all the ADP was consumed, and then the maximal uncoupler-stimulated respiration was measured using carbonyl cyanide-ptrifluoromethoxyphenylhydrazone (FCCP) (state 3u). Injections were as follows: port A, 
$50 \mu \mathrm{L}$ of $40 \mathrm{mM}$ ADP (4 mM final); port B, $55 \mu \mathrm{L}$ of $30 \mu \mathrm{g} / \mathrm{mL}$ oligomycin $(3 \mu \mathrm{g} / \mathrm{mL}$ final); port C, $60 \mu \mathrm{L}$ of $40 \mu \mathrm{M}$ FCCP ( $4 \mu \mathrm{M}$ final); and port D, $65 \mu \mathrm{L}$ of $40 \mu \mathrm{M}$ antimycin $\mathrm{A}(4 \mu \mathrm{M}$ final). All data were expressed in picomoles per minute per milligram of protein. The respiratory control ratio (RCR) was calculated using the highest OCR point in state $3 \mathrm{o}$ and the lowest point in state 4 Merck Life Science S.L.U. (Madrid, Spain) was the manufacturer of the succinate, malate, glutamate, pyruvate, ADP, oligomycin, FCCP, and antimycin

\subsection{Quantification of $\beta-R A$ and $4-H B$ Levels in Mice Tissues}

Tissues from the mice were homogenized in water. The homogenate samples were then treated with a solution of methanol/water $(80: 20, v / v)$, shook for $1 \mathrm{~min}$, sonicated for $15 \mathrm{~min}$, and then centrifuged at $5000 \times \mathrm{g}$ for $25 \mathrm{~min}$ at $4{ }^{\circ} \mathrm{C}$.

The supernatants were analyzed using a Thermo Scientific ${ }^{\mathrm{TM}}$ UltiMate $^{\mathrm{TM}} 3000$ UHPLC system (Waltham, MA, USA), consisting of an UltiMate ${ }^{\mathrm{TM}} 3000$ UHPLC RS binary pump and an UltiMate ${ }^{\mathrm{TM}} 3000$ UHPLC sample manager coupled to a Thermo Scientific ${ }^{\mathrm{TM}} \mathrm{Q}$ Exactive $^{\mathrm{TM}}$ Focus Hybrid Quadrupole-Orbitrap ${ }^{\mathrm{TM}}$ detector of a mass spectrometer (MS/MS) with electrospray ionization in negative mode (Waltham, Massachusetts, United States). The analytical separation column was a Hypersil GOLD ${ }^{\mathrm{TM}} \mathrm{C} 18,3 \mu \mathrm{m}, 4.6 \mathrm{~mm} \times 150 \mathrm{~mm}$ column (Thermo Scientific, Madrid, Spain) and the flow rate was $0.6 \mathrm{~mL} / \mathrm{min}$. The mobile phase consisted of two solutions: eluent $\mathrm{A}\left(\mathrm{H}_{2} \mathrm{O}+0.1 \%\right.$ formic acid, MS grade, Thermo Scientific, Madrid, Spain) and eluent B (acetonitrile $+0.1 \%$ formic acid, MS grade, Thermo Scientific, Madrid, Spain). Samples were eluted over $30 \mathrm{~min}$ with the following gradient: 0 min, $95 \%$ eluent A; 0-25 min, 70\% eluent A; 25-25.1 min, 95\% eluent A; $25.1-30 \mathrm{~min}$, $95 \%$ eluent $\mathrm{A}$. The capillary and auxiliary gas temperatures were set at 275 and $450{ }^{\circ} \mathrm{C}$, respectively. The sheath gas flow rate used was at 55 arbitrary units, the auxiliary gas flow rate used was at 15 arbitrary units, and the sweep gas flow was used at 3 arbitrary units. Mass spectrometry analyses were carried out in full scan mode between 110 and 190 uma. To quantify the levels of 4-HB (Merck Life Science S.L.U, Madrid, Spain) and $\beta-R A$, we used a standard curve with both compounds at concentrations of 100, 10, and $1 \mathrm{ng} / \mathrm{mL}$.

\subsection{Statistical Analysis}

The number of animals in each group was calculated in order to detect gross $\sim 60 \%$ changes in the biomarker measurements (based upon alpha $=0.05$ and power of beta $=0.8$ ). We used the application available at http:/ / www.biomath.info/power/index.htm accessed on 14 September 2021. Animals were genotyped and randomly assigned to experimental groups in separate cages by the technician of the animal facility. Most statistical analyses were performed using the Prism 9 scientific software. Data are expressed as the mean \pm SD of five to ten experiments per group. A one-way ANOVA with Tukey's post hoc test was used to compare the differences between the three experimental groups. Studies with two experimental groups were evaluated using the Mann-Whitney (nonparametric) test. A $p$-value of $<0.05$ was considered to be statistically significant. The survival curve was analyzed using log-rank (Mantel-Cox) and the Gehan-Breslow-Wilcoxon tests. The statistical tests that were used for the transcriptomics and proteomics analyses are described in their respective sections.

\section{Results}

3.1. $\beta$-RA Induced Phenotypic and Morphological Benefits against Both Age-Related Obesity and Mitochondrial Encephalopathy Due to CoQ Deficiency

$\beta$-RA was incorporated into the chow of both wild-type and $\operatorname{Cog} 9^{R 239 X}$ mice at a concentration of $0.33 \%(w / w)$, which gave a dose of $0.4-0.7 \mathrm{~g} / \mathrm{kg}$ b.w./day, considering the animal food intake, which was similar in all groups (Figure 1A-C). This low dose of $\beta$-RA improved the survival of $\operatorname{Coq}^{+/+}$mice at the old stage of life (Figure 1D,E), where $87 \%$ of the treated $\mathrm{Coq}^{+/+}$mice survived compared with $62 \%$ of the untreated mice. However, the survival curve became similar to the survival curve of untreated animals after 28 months of age. Similarly, the low-dose treatment of $\beta$-RA also improved the survival of Coq9 $9^{R 239 X}$ 
mice (Figure 1D), and we even observed a maximal lifespan higher than the maximal lifespan reported when $\operatorname{Coq} 9^{R 239 X}$ mice were treated with a high dose of $\beta$-RA [22].

A

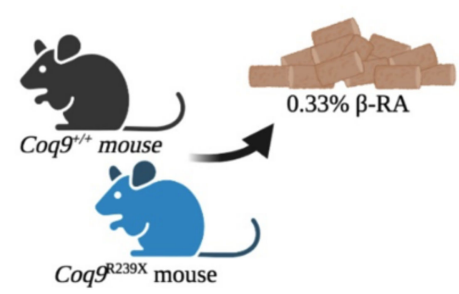

D

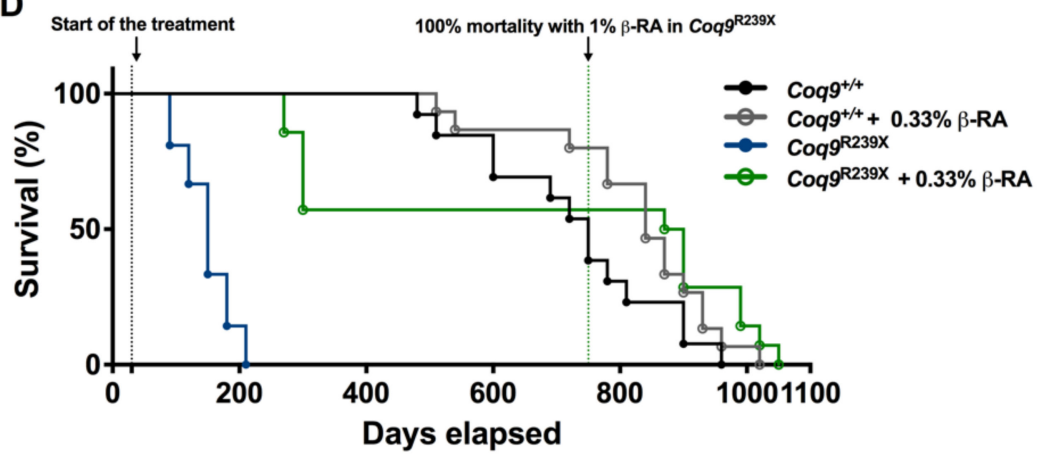

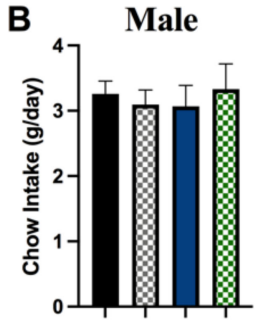

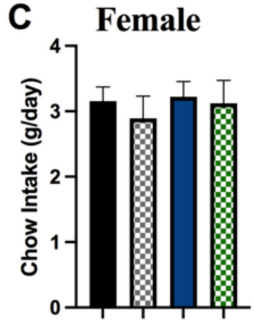

E

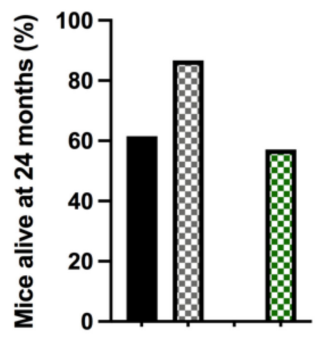

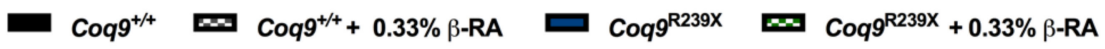

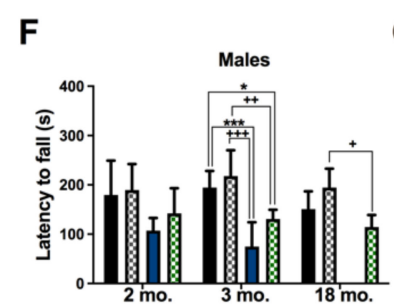

G

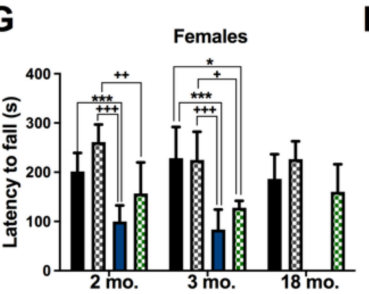

H Males I

I Females

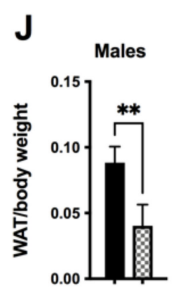

K

$\mathbf{N}$

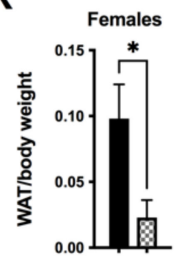

$\mathbf{L}$

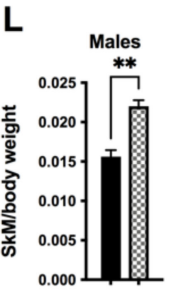

M
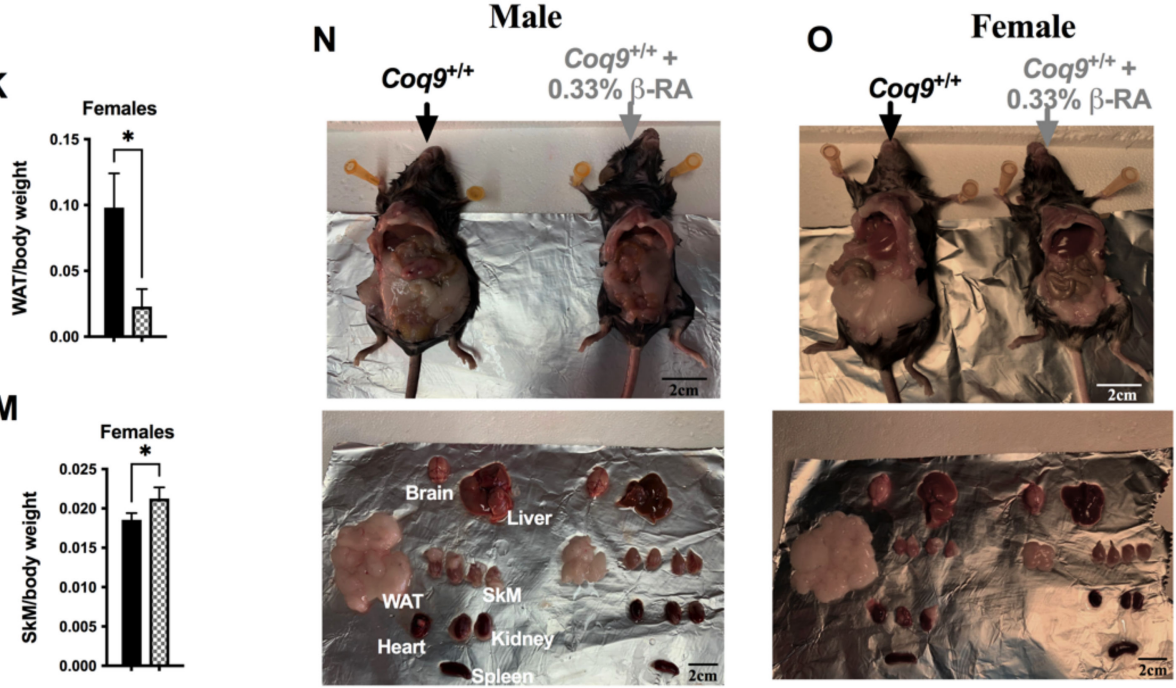

Figure 1. Survival and phenotypic characterization of $\operatorname{Coq}^{+/+}$and $\operatorname{Cog} 9^{R 239 X}$ mice during the supplementation with $0.33 \%$ $\beta$-RA. (A) Schematic figure of the $\beta$-RA treatment in $\mathrm{Cog}^{+/+}$and Coq9 ${ }^{\mathrm{R} 239 \mathrm{X}}$ mice. (B,C) Daily food intake in male and female $\mathrm{Coq}^{+/++}$and $\operatorname{Cog} 9^{\mathrm{R} 239 \mathrm{X}}$ mice. (D) Survival curve of the $\operatorname{Coq} 9^{+/+}$mice, $\operatorname{Coq} 9^{+/+}$mice given $0.33 \% \beta$-RA supplementation, $\operatorname{Coq} 9^{R 239 X}$ mice, and $\operatorname{Cog}^{R 239 X}$ mice given $0.33 \% \beta$-RA supplementation. The treatments started at 1 month of age (log-rank (Mantel-Cox) test or Gehan-Breslow-Wilcoxon test; $\mathrm{Cog}^{9^{+/+}}$mice, $n=13$; $\mathrm{Cog}^{9^{+/+}}$mice under $0.33 \% \beta$-RA supplementation, $n=15$; $\operatorname{Cog} 9^{R 239 X}$ mice, $n=21$; $\operatorname{Cog} 9^{R 239 X}$ mice under $0.33 \% \beta$-RA supplementation, $n=14$ ). (E) Percentage of mice alive at 
24 months of age. (F,G) Rotarod test of male and female $\operatorname{Coq} 9^{+/+}$mice, Coq $9^{+/+}$mice given $0.33 \%$-RA supplementation, $\operatorname{Coq} 9^{R 239 X}$ mice, and $\operatorname{Coq} 9^{R 239 X}$ mice given $0.33 \%$-RA supplementation. (H,I) Body weight of male and female Coq $9^{+/+}$mice, $\mathrm{Coq}^{+/+}$mice given $0.33 \% \beta$-RA supplementation, $\operatorname{Coq} 9^{R 239 X}$ mice, and $\operatorname{Coq} 9^{R 239 X}$ mice given $0.33 \%$-RA supplementation. (J-M) Weight of the epididymal, mesenteric, and inguinal white adipose tissue (WAT) $(\mathbf{J}, \mathbf{K})$ and hind legs skeletal muscle $(\mathrm{SKM})(\mathbf{L}, \mathbf{M})$ relative to the total body weight in male and female $\operatorname{Cog} 9^{+/+}$mice, and $\operatorname{Cog} 9^{+/+}$mice given $0.33 \% \quad \beta-\mathrm{RA}$ supplementation at 18 months of age. $(\mathbf{N}, \mathbf{O})$ Representative images of male $(\mathrm{N})$ and female $(\mathrm{O})$ mice and their tissues at 18 months of age, both untreated and treated. Data are expressed as mean \pm SD. ${ }^{*} p<0.05,{ }^{* *} p<0.01,{ }^{* * *} p<0.001$, differences versus $\operatorname{Coq} 9^{+/+} ;+p<0.05,++p<0.01,+++p<0.001, \operatorname{Co} 9^{+/+}$mice given $0.33 \% \beta$-RA supplementation (one-way ANOVA with Tukey's post hoc test or Mann-Whitney (nonparametric) test; $n=5-34$ for each group).

The encephalopathic features of $\operatorname{Coq} 9^{R 239 X}$ mice result in characteristics of lower locomotor activity and increased uncoordination. However, the $\operatorname{Cog} 9^{R 239 X}$ mice improved after $\beta$-RA administration compared to the untreated $\operatorname{Cog} 9^{R 239 X}$ mice. The treatment did not significantly affect the results of the rotarod test in wild-type animals (Figure 1F,G). Both the $\mathrm{Cog}^{+/+}$and $\operatorname{Coq} 9^{R 239 X}$ mice treated with $\beta$-RA had a healthy appearance (Movies S1 and S2).

The body weights were significantly reduced in both male and female $\mathrm{Cog}^{+/+}$mice after one month of treatment, reaching a maximal weight of about $28 \mathrm{~g}$ in males and $23 \mathrm{~g}$ in females at seven months of age. These weights were then maintained throughout the remaining life of the animals (Figure 1H,I) (Movie S3). Curiously, the treatment with $\beta$-RA slightly increased the body weights of the $\operatorname{Coq} 9^{R 239 X}$ mice, which usually weighed less than their untreated $\operatorname{Cog}^{+/+}$littermates (Figure $1 \mathrm{H}, \mathrm{I}$ ). Consequently, both treated $\mathrm{Co} 9^{+/+}$and treated $\operatorname{Coq} 9^{R 239 X}$ mice had similar body weights. The reduced body weight in $\operatorname{Cog} 9^{+/+}$mice after the $\beta$-RA treatment was mainly caused by the prevention of accumulation of WAT (Figure $1 \mathrm{~J}, \mathrm{~K}, \mathrm{~N}, \mathrm{O}$ ) while still preserving the content, weight, and strength of the skeletal muscle (Figures $1 \mathrm{~L}-\mathrm{O}$ and $\mathrm{S} 1$ ).

The most notable histopathological features of $\mathrm{CoQ}_{10}$ deficiency in the $\operatorname{Coq} 9^{R 239 X}$ mice were cerebral spongiosis and reactive astrogliosis (Figure 2(A1-D1)), together with the reduced body weight due to, at least in part, to the decreased content in WAT (Figure S2(A1,B1)). Low-dose $\beta$-RA supplementation in the $\operatorname{Coq} 9^{R 239 X}$ mice for two months decreased the characteristic spongiosis (marked by an arrow, Figure 2(E1,F1)) and reactive astrogliosis, determined using the GFAP-positive cells (marked by an arrow, Figure 2(G1,H1)), with no changes in the liver (Figure S2(C1-J1)). These results were similar to the therapeutic effect that was previously reported with a higher dose [22]. In Cog $9^{+/+}$mice, $\beta$-RA supplementation for two months did not produce significant morphological alterations in the brain (Figure 2(I1-P1)), liver (Figure S2(K1-M1) and (Q1-S1)), kidneys (Figure S2(N1-P1) and (T1-V1), spleen (Figure S(2V1-X1) and (C2,D2)), heart (Figure (S2Y1,Z1) and (E2,F2)), or small intestine (Figure S2(A2,B2) and (G2,H2)), and the blood and urine markers of the renal and hepatic functions did not reveal any abnormality (Table S1). 

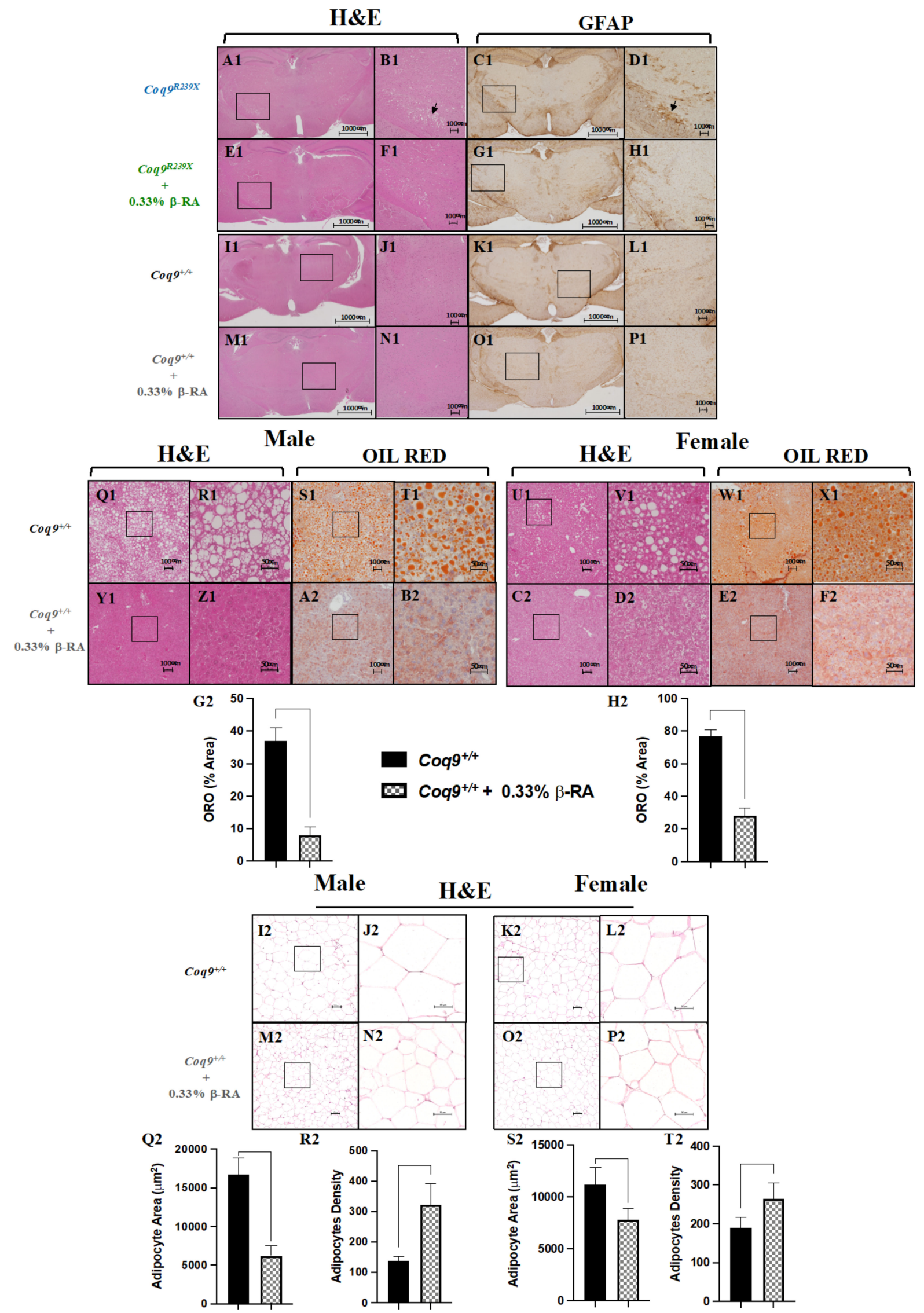

Figure 2. Morphological evaluation of symptomatic tissues from $\operatorname{Coq} 9^{R 239 X}$ and $\operatorname{Co} 9^{+/+}$mice under the supplementation with $0.33 \%$ $\beta$-RA. (A1-P1) H\&E stain and anti-GFAP immunohistochemistry in sections of the diencephalon from Coq $9^{R 239 X}$ 
mice (A1-D1), $\operatorname{Coq} 9^{R 239 X}$ mice given $0.33 \%$ $\beta$-RA supplementation (E1-H1), Coq9 $9^{+/+}$mice (I1-L1), Coq9 $9^{+/+}$mice given $0.33 \%$ $\beta$-RA supplementation (M1-P1) at 3 months of age. Scale bars: $1000 \mu \mathrm{m}$ left, $100 \mu \mathrm{m}$ right. Black arrows show areas of spongiosis and astrogliosis. (Q1-F2) H\&E and Oil Red stains in sections of the liver at 18 months of age from male (Q1-T1) and female (U1-X1) Coq9 $9^{+/+}$mice and male (Y1-B2) and female (C2-F2) Coq $9^{+/+}$mice given 0.33\% $\beta$-RA supplementation. Scale bars: $100 \mu \mathrm{m}$ left, $50 \mu \mathrm{m}$ right. (G2-H2) Percentage of the area corresponding to the Oil Red O stains in sections of the liver at 18 months of age from $\operatorname{Cog} 9^{+/+}$mice and $\operatorname{Cog} 9^{+/+}$mice given $0.33 \% \beta-R A$ supplementation. (I2-P2) H\&E stains in sections of the epididymal WAT at 18 months of age from male (G2,H2) and female (I2,J2) Coq9 $9^{+/+}$mice and male $(\mathbf{K} 2, \mathbf{L} 2)$ and female (M2,N2) Coq $9^{+/+}$mice given 0.33\% $\beta$-RA supplementation. Scale bars: $100 \mu \mathrm{m}$ left, $50 \mu \mathrm{m}$ right. (Q2-T2) Average of the area of each adipocyte and the adipocytes density in sections of the epididymal WAT at 18 months of age from $\operatorname{Coq} 9^{+/+}$mice and $\operatorname{Coq} 9^{+/+}$mice given $0.33 \% \beta$-RA supplementation. Data are expressed as mean \pm SD. ${ }^{*} p<0.05$, differences versus Coq9 ${ }^{+/+}$(Mann-Whitney (nonparametric) test; $n=4-6$ for each group).

At 18 months of age, the livers of both male and female wild-type mice showed features of steatosis (Figure 2(Q1-X1) and Figure 2(G2,H2)). Chronic supplementation with $\beta$-RA dramatically reduced the signs of hepatic steatosis (Figure 2(Y1-F2) and Figure 2(G2,H2)). Non-alcoholic hepatic steatosis is frequently associated with fat accumulation. Consequently, the epididymal WAT showed characteristics of hypertrophy in both the male and female $\operatorname{Cog}^{+/+}$mice at 18 months of age (Figure 2(I2-L2) and Figure 2(Q2-T2)), with adipocytes that were bigger in size and lower in number per area. $\beta$-RA supplementation suppressed the epididymal WAT hypertrophy in both the male and female Coq9 $9^{+/+}$mice at 18 months of age (Figure 2(M2-P2) and Figure 2(Q2-T2)). At 18 months of age, no major alterations were found in the brains or kidneys (Figure S2).

\section{2. $\beta-R A$ Led to Bioenergetics Improvement in Coq9 $9^{R 239 X}$ Mice through Its Direct Participation in the CoQ Biosynthetic Pathway}

The decrease in $\mathrm{DMQ}_{9}$ was previously reported as the main therapeutic mechanism of a high dose of $\beta$-RA in the treatment in Coq $9^{R 239 X}$ mice, although the effects in the CoQ biosynthetic pathway in wild-type animals were not evaluated [22]. Thus, we evaluated whether a lower dose of $\beta$-RA interferes with CoQ biosynthesis in both $\operatorname{Coq} 9^{+/+}$ and $\operatorname{Coq} 9^{R 239 X}$ mice. In Coq $9^{+/+}$mice, $\beta$-RA induced very mild changes in the tissue levels of $\mathrm{CoQ}_{9}, \mathrm{CoQ}_{10}$, and $\mathrm{DMQ}_{9}$ (Figures 3(A1-L1), S3A, S4A-D and S5A-B). The levels of $\mathrm{CoQ}_{9}$ were similar in the brain, kidneys, liver heart, and WAT of untreated and treated wild-type mice, whilst in skeletal muscle, the $\beta$-RA induced a mild reduction in the levels of $\mathrm{CoQ}_{9}$ (Figures 3(A1-D1), S4A and S5A). DMQ 9 was undetectable in the tissues of untreated wild-type mice, and $\beta$-RA supplementation induced the accumulation of very low levels of $\mathrm{DMQ}_{9}$ in the kidneys, liver, skeletal muscle, and WAT, but not in the brain or heart (Figures 3(I1-L1), S4C and S5B). Consequently, the ratio $\mathrm{DMQ}_{9} / \mathrm{CoQ}_{9}$ was not significantly altered in $\operatorname{Cog} 9^{+/+}$mice treated with $\beta-\mathrm{RA}$, as it was observed in the untreated Coq9 $9^{R 239 X}$ mice (Figure 3(M1-P1)). In $\operatorname{Cog} 9^{R 239 X}$ mice, $\beta$-RA administration induced a mild increase in $\mathrm{CoQ}_{9}$ in the kidneys (Figures 3(B1) and S3B) compared with untreated $\operatorname{Coq} 9^{R 239 X}$ mice. However, the levels of $\mathrm{CoQ}_{9}$ did not change in the brain, liver, skeletal muscle, or heart of $\operatorname{Coq} 9^{R 239 X}$ mice after the $\beta$-RA treatment (Figures 3A1,C1,D1 and S4A). Remarkably, the levels of $\mathrm{DMQ}_{9}$ and, consequently, the $\mathrm{DMQ}_{9} / \mathrm{CoQ}_{9}$ ratio, were significantly decreased in the kidneys (Figures 3(J1,N1) and S3B), liver (Figure 3(K1,O1)), skeletal muscle (Figure 3L1,P1), and heart (Figure S4C,D) of the Coq9 ${ }^{R 239 X}$ mice treated with $\beta$-RA compared with the untreated $\operatorname{Coq} 9^{R 239 X}$ mice. However, $\beta$-RA did not reduce the levels of $\mathrm{DMQ}_{9}$ or the $\mathrm{DMQ}_{9} / \mathrm{CoQ}_{9}$ ratio in the brain of the Coq9 ${ }^{R 239 X}$ mice (Figure 3(I1,M1)), as it was also reported in the treatment with the higher dose of $\beta$-RA [22]. Therefore, the effect of $\beta$-RA on CoQ metabolism in the $\operatorname{Cog} 9^{R 239 X}$ mice in this study was similar to the effect previously reported with a higher dose of $\beta-R A$, i.e., a decrease in the DMQ/CoQ ratio in peripheral tissues [22]. 


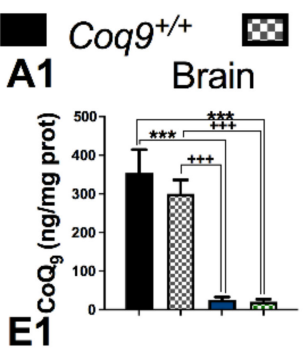

E1
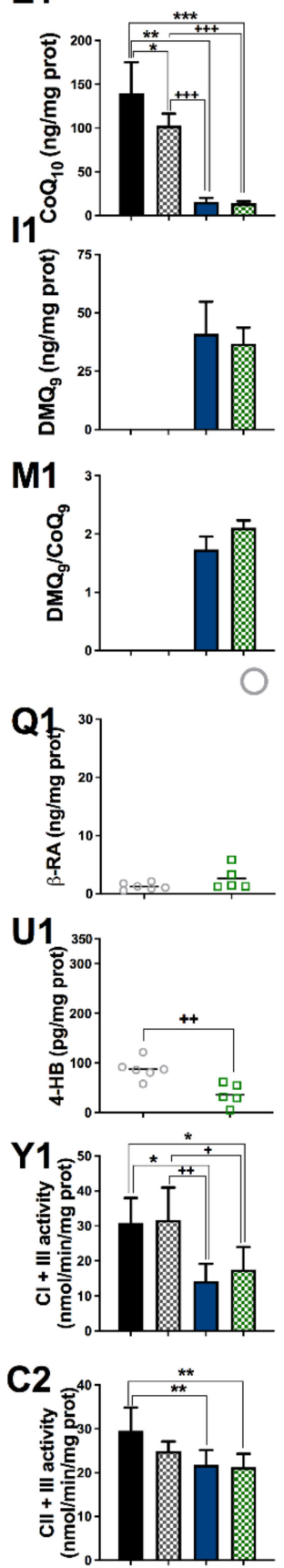
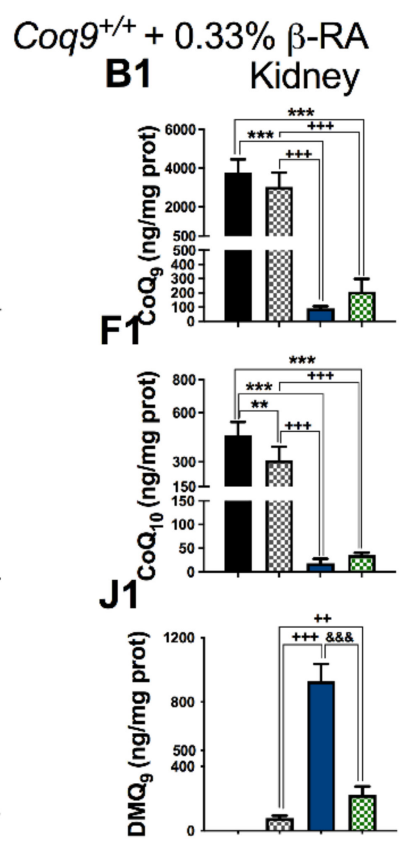

N1
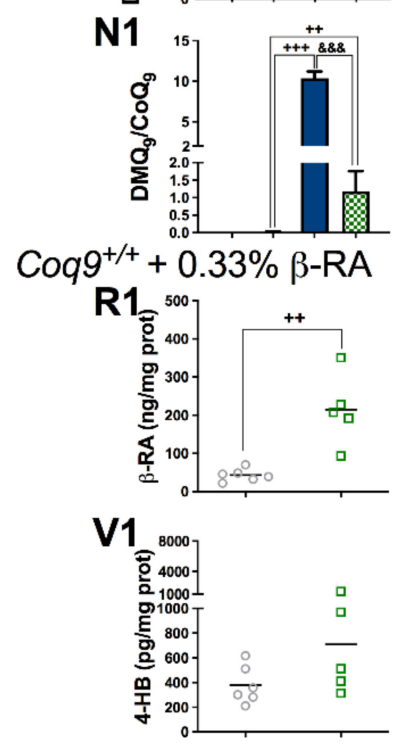

Z1

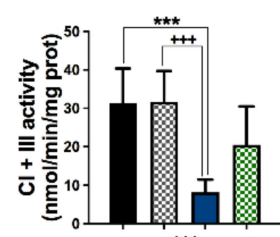

D2

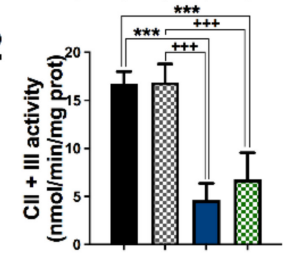

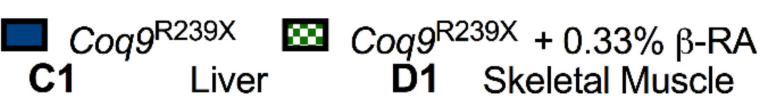

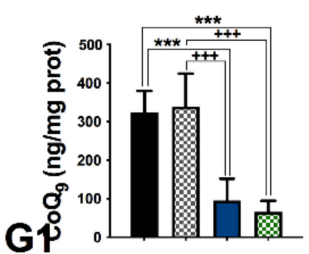

GP

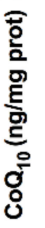

K1

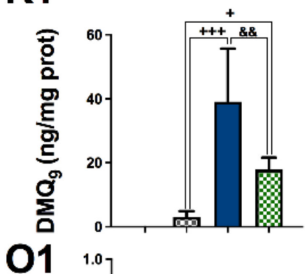

01
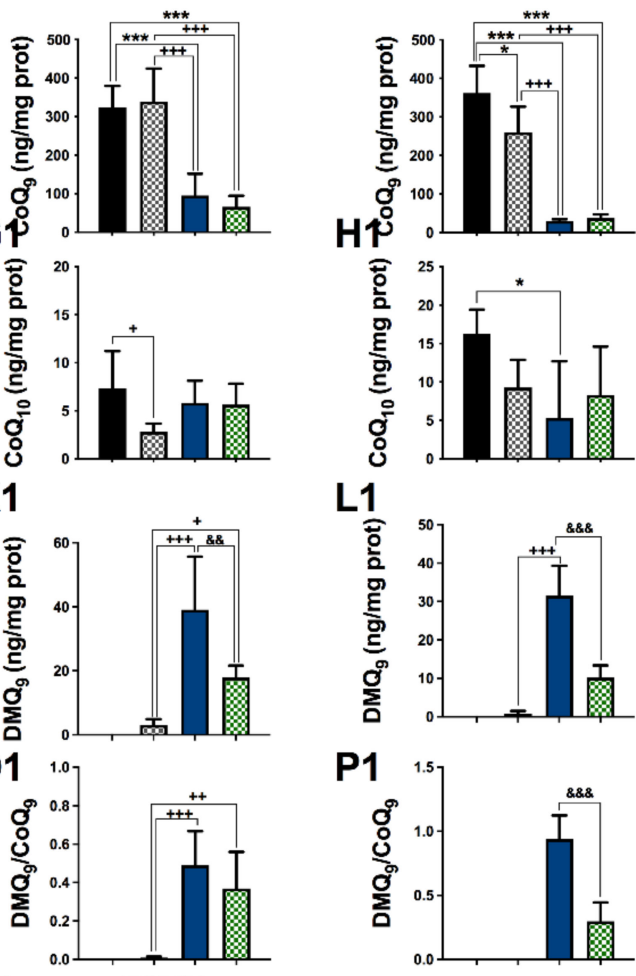

$\mathrm{HT}$

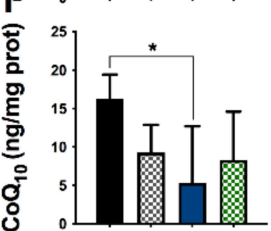

L1

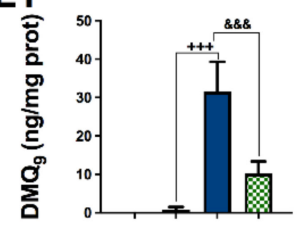

P1

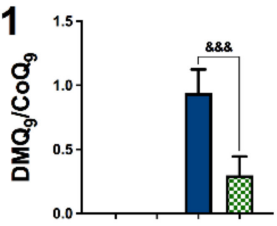

Coq9 $9^{R 239 X}+0.33 \% \beta-R A$
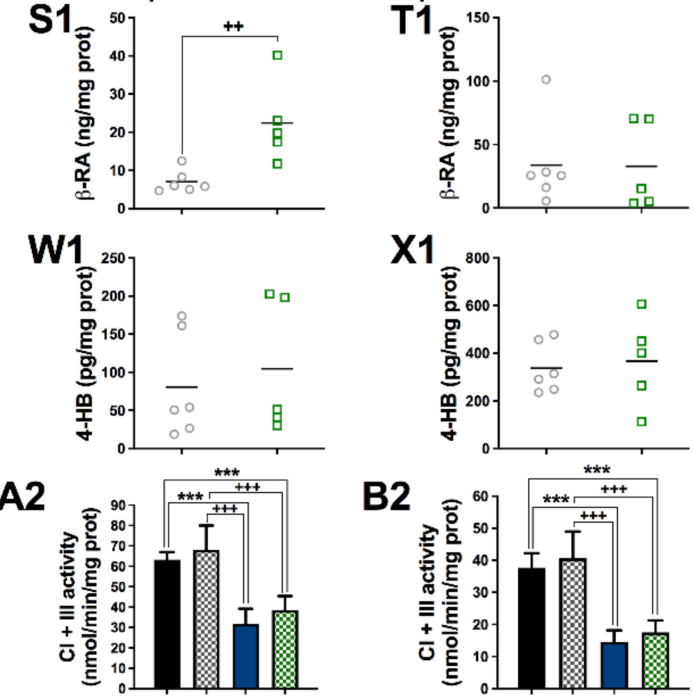

F2

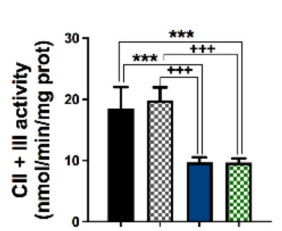

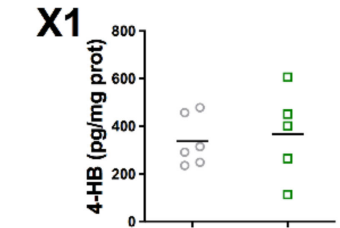

B2

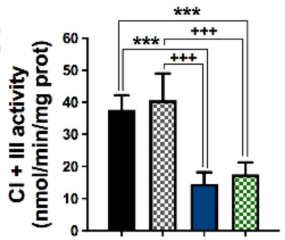

G2

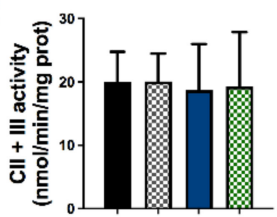

Figure 3. CoQ metabolism and mitochondrial function in the tissues from the $\operatorname{Coq} 9^{+/+}$mice, $\operatorname{Coq} 9^{+/+}$mice given supplementation with $0.33 \% \beta-R A, \operatorname{Coq} 9^{R 239 X}$ mice, and $\operatorname{Coq} 9^{R 239 X}$ mice given supplementation with $0.33 \% \beta$-RA. (A1-D1) Levels of $\mathrm{CoQ}_{9}$ in the brain (A1), kidneys (B1), liver (C1), and hind legs skeletal muscle (D1) from the Coq $9^{+/+}$mice, Coq $9^{+/+}$mice given the $0.33 \% \beta$-RA treatment, $\operatorname{Coq} 9^{R 239 X}$ mice, and $\operatorname{Coq} 9^{R 239 X}$ mice given the $0.33 \% \beta$-RA treatment. (E1-H1) Levels of CoQ 10 in the brain (E1), kidneys (F1), liver (G1) and hind legs skeletal muscle (H1) from the $\operatorname{Coq} 9^{+/+}$mice, $\operatorname{Cog} 9^{+/+}$mice given the $0.33 \% \beta$-RA treatment, $\operatorname{Cog} 9^{R 239 X}$ mice, and $\operatorname{Cog} 9^{R 239 X}$ mice given the $0.33 \% \beta$-RA treatment. (I1-L1) Levels of DMQ ${ }_{9}$ in the 
brain (I1), kidneys (J1), liver (K1), and hind legs skeletal muscle (L1) from Coq $9^{+/+}$mice, Coq $9^{+/+}$mice given the $0.33 \%$ $\beta$-RA treatment, $\operatorname{Coq} 9^{R 239 X}$ mice, and $\operatorname{Coq} 9^{R 239 X}$ mice given the $0.33 \% \beta$-RA treatment. Note that DMQ ${ }_{9}$ was not detected in samples from the Coq9 $9^{+/+}$mice. (M1-P1) $\mathrm{DMQ}_{9} / \mathrm{CoQ}_{9}$ ratio in the brain (M1), kidneys (N1), liver (O1), and hind legs skeletal muscle (P1) from the $\operatorname{Coq} 9^{+/+}$mice, $\operatorname{Coq} 9^{+/+}$mice given the $0.33 \% \beta$-RA treatment, $\operatorname{Coq} 9^{R 239 X}$ mice, and Coq9 $9^{R 239 X}$ mice given the $0.33 \% \beta$-RA treatment. (Q1-X1) Levels of $\beta$-RA in the brain (Q1), kidneys (R1), liver (S1), and hind legs skeletal muscle (T1) from the $\operatorname{Coq} 9^{+/+}$mice given the $0.33 \% \beta-R A$ treatment and $\operatorname{Coq} 9^{R 239 X}$ mice given the $0.33 \% \beta-R A$ treatment. $\beta$-RA was undetectable in the $\operatorname{Cog} 9^{+/+}$mice and $\operatorname{Coq} 9^{R 239 X}$ mice. (U1-X1) Levels of 4-HB in the brain (U1), kidneys (V1), liver (W1), and hind legs skeletal muscle (X1) from the Coq $9^{+/+}$mice given the $0.33 \% \beta$-RA treatment and Coq9 $9^{R 239 X}$ mice given the $0.33 \% \beta$-RA treatment. (Y1-B2) Complex I + III (CI + III) activities in the brain (Y1), kidneys (Z1), liver (A2), and hind legs skeletal muscle (B2) from the Coq $9^{+/+}$mice, Coq $9^{+/+}$mice given the $0.33 \%$-RA treatment, Coq9R239X mice, and Coq9 $9^{R 239 X}$ mice given the $0.33 \% \beta$-RA treatment. (C2-G2) Complex II + III (CII + III) activities in the brain (C2), kidneys (D2), liver (F2), and hind legs skeletal muscle (G2) from the $\operatorname{Coq} 9^{+/+}$mice, Coq $9^{+/+}$mice given the $0.33 \%$ $\beta$-RA treatment, $\operatorname{Cog} 9^{R 239 X}$ mice, and $\operatorname{Cog} 9^{R 239 X}$ mice given the $0.33 \% \beta$-RA treatment. Tissues from the mice at 3 months of age. Data are expressed as mean $\pm \mathrm{SD}$. ${ }^{*} p<0.05,{ }^{* *} p<0.01,{ }^{* * *} p<0.001$, differences versus $\operatorname{Co} 9^{+/+}$. $+p<0.05,++p$ $<0.01,+++p<0.001$, differences versus the Coq $9^{+/+}$mice given the $0.33 \% \beta$-RA treatment. \&\& $p<0.01, \& \& \& p<0.001$, differences versus $\operatorname{Coq} 9^{R 239 X}$. One-way ANOVA with Tukey's post hoc test or Mann-Whitney (nonparametric) test; $n=5-8$ for each group.

The tissue-specific reduction in the levels of $\mathrm{DMQ}_{9}$ in $\operatorname{Cog}^{2239 \mathrm{X}}$ mice seemed to correlate with the increase in $\beta$-RA since the levels of $\beta$-RA were higher in the kidneys (Figure 3R1), liver (Figure 3(S1)), skeletal muscle (Figure 3(T1)), and heart (Figure S4E) than in the brain (Figure 3Q1) of $\operatorname{Coq} 9^{R 239 X}$ mice. The levels of 4-HB, the natural precursor for $\mathrm{CoQ}$ biosynthesis, did not increase in response to the treatment with $\beta$-RA in any tissue of either the $\mathrm{Cog}^{+/+}$or $\operatorname{Cog} 9^{R 239 \mathrm{X}}$ mice (Figures $3 \mathrm{U} 1-\mathrm{X} 1$ and $\mathrm{S} 4 \mathrm{~F}$ ).

Bioenergetically, the treatment with $\beta$-RA did not produce any changes in the brain in either the Coq9 $9^{+/+}$or $\operatorname{Coq} 9^{R 239 X}$ mice (Figures $3(\mathrm{Y} 1, \mathrm{C} 2)$ and S6A,C), but it did increase the activities of complexes I + III and II + III (Figure 3(Z1,D2)) and mitochondrial respiration (Figure S6B,D) in the kidneys of the treated Coq9 ${ }^{R 239 X}$ mice compared to the untreated Coq $9^{R 239 X}$ mice. These data are comparable to those reported for the treatment with the high dose of $\beta$-RA [22], suggesting that the decrease in the $\mathrm{DMQ} / \mathrm{CoQ}$ ratio was responsible for the bioenergetics improvement. Other tissues did not experience major changes in mitochondrial bioenergetics in $\mathrm{Cog}^{+/+}$or $\operatorname{Coq} 9^{R 239 \mathrm{X}}$ mice (Figures $3(\mathrm{Y} 1-\mathrm{G} 2)$ and S4G-H).

Because $\beta-\mathrm{RA}$ is an analog of $4-\mathrm{HB}$, its effects at reducing $\mathrm{DMQ}_{9}$ in Coq9 ${ }^{R 239 X}$ mice were most likely due to its competition with 4-HB when entering the CoQ biosynthetic pathway through the activity of COQ2. To investigate this hypothesis, we supplemented the $\operatorname{Coq}^{+/+}$and $\operatorname{Coq} 9^{R 239 X}$ mice with an equal amount of 4-HB and $\beta$-RA incorporated into the chow. Because COQ2 has more of an affinity for 4-HB than for $\beta-\mathrm{RA}$, in conditions of equal amounts of both compounds, COQ2 will preferably use 4-HB. Accordingly, the co-administration of 4-HB and $\beta$-RA suppressed the mild inhibitory effect of $\beta$-RA over $\mathrm{CoQ}_{9}$ biosynthesis in the skeletal muscle (Figure $4 \mathrm{D}$ ) and $\mathrm{CoQ}_{10}$ biosynthesis in the brain, kidneys, and liver (Figure $4 \mathrm{~F}-\mathrm{H}$ ) of the $\mathrm{Coq}^{+/+}$mice (compare with Figure 3). Moreover, $\mathrm{CoQ}_{9}$ increased in the brain (Figure $4 \mathrm{~A}$ ) and the kidneys (Figure 4B) of the Coq $9^{+/+}$mice treated with the combination of $4-\mathrm{HB}$ and $\beta$-RA compared to the untreated Coq $9^{+/+}$mice. In the $\operatorname{Cog} 9^{R 239 X}$ mice, the untreated and treated groups showed similar levels of both $\mathrm{CoQ}_{9}$ (Figure $4 \mathrm{~A}-\mathrm{E}$ ) and $\mathrm{CoQ}_{10}$ (Figure $4 \mathrm{~F}-\mathrm{J}$ ) in all tissues. Importantly, the reduction in the levels of $\mathrm{DMQ}_{9}$ and the $\mathrm{DMQ}_{9} / \mathrm{CoQ}_{9}$ ratio induced by $\beta$-RA (Figures 3, S3 and S4) in the $\operatorname{Coq} 9^{R 239 X}$ mice seemed to be suppressed by the co-administration of $4-\mathrm{HB}$ and $\beta$-RA (Figure $4 \mathrm{~K}-\mathrm{T}$ ). Consequently, the co-administration of 4 -HB and $\beta$-RA suppressed the increase in survival of the $\operatorname{Cog} 9^{R 239 X}$ mice that was found after the treatment with $\beta$-RA alone (Figure $4 \mathrm{U}$ ). Together, these data demonstrated that $\beta$-RA acted therapeutically in the $\operatorname{Cog} 9^{R 239 X}$ mice by entering the CoQ biosynthetic pathway, leading to a reduction in the levels of $\mathrm{DMQ}_{9}$. 

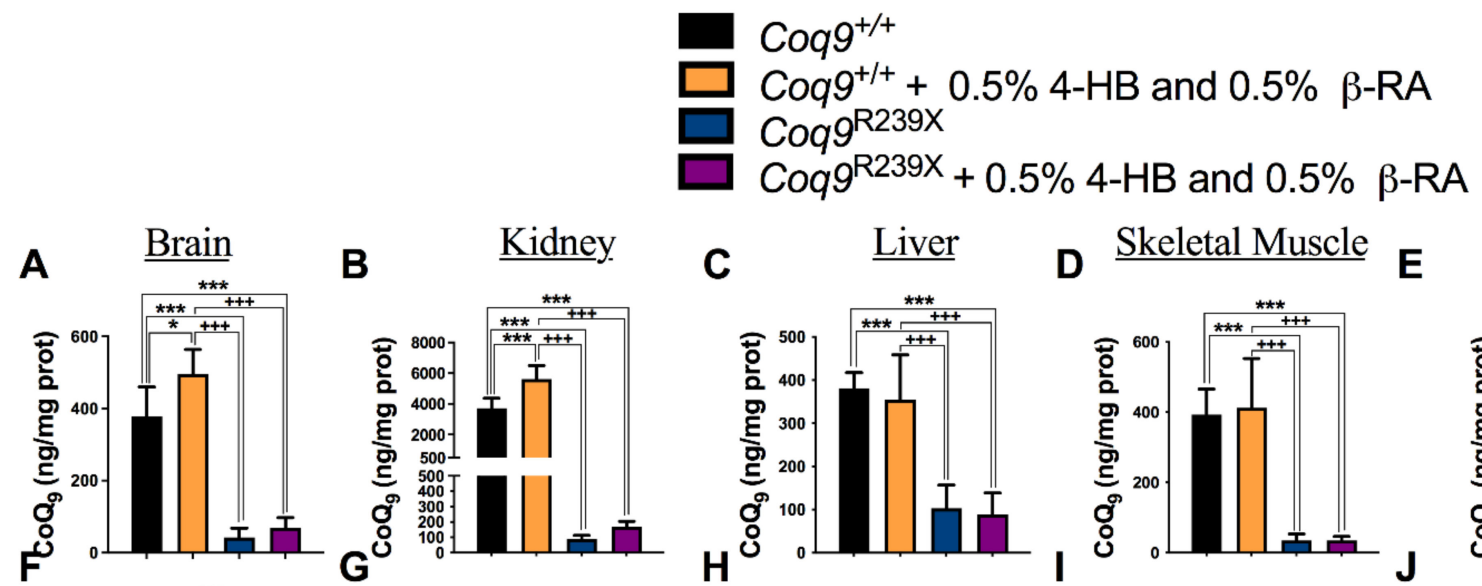

D $\underline{\text { Skeletal Muscle }}$ E

$\underline{\text { Heart }}$
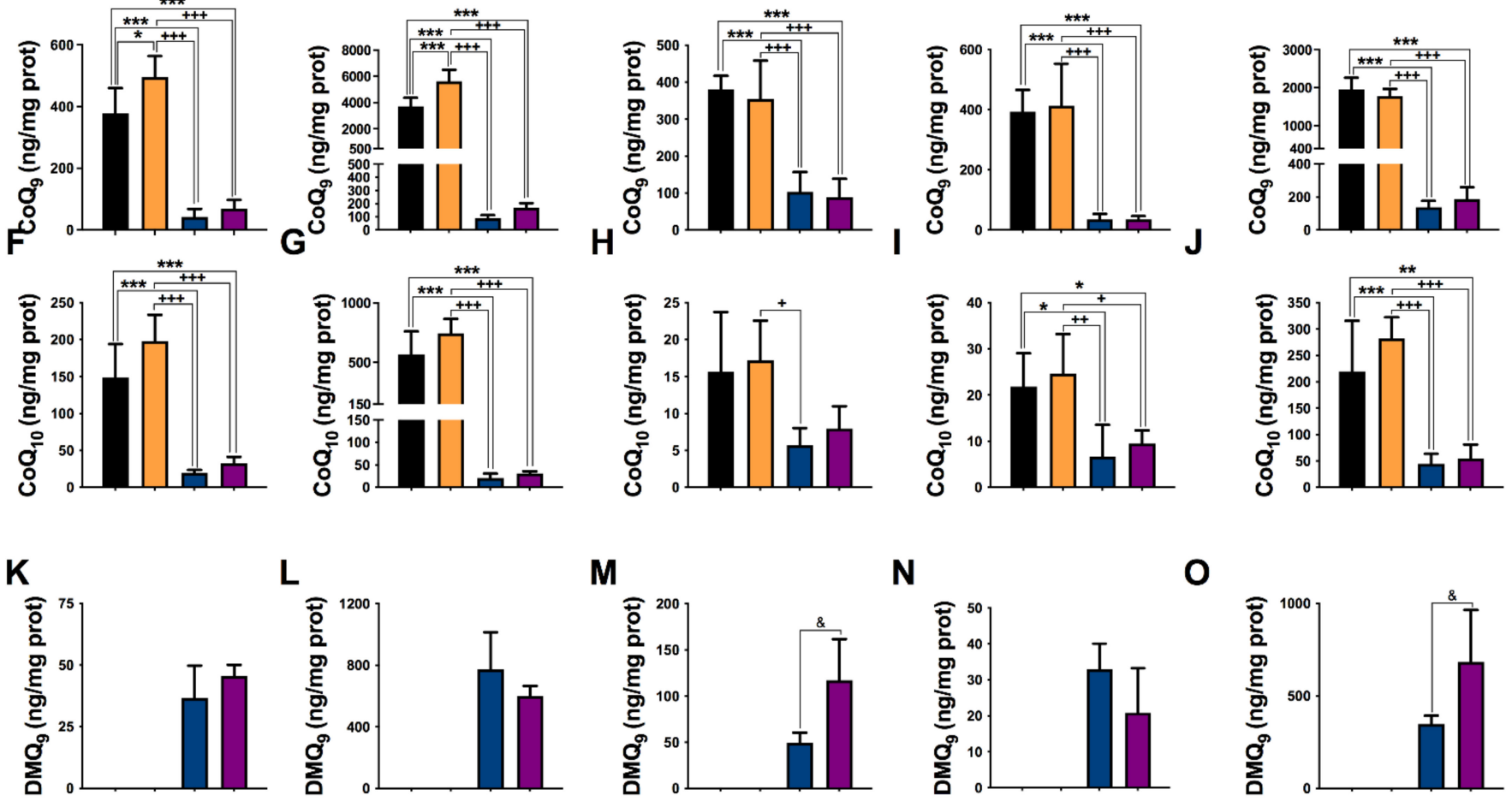

M
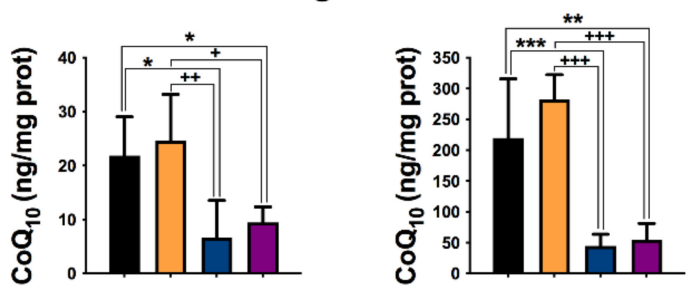

$\mathbf{P}$

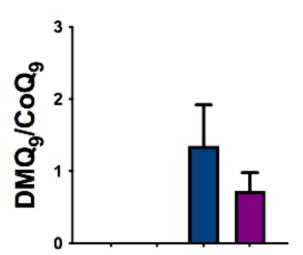

$\mathbf{Q}$

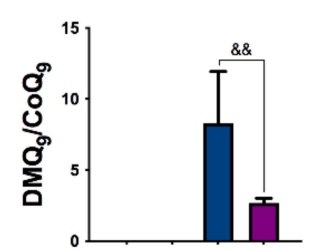

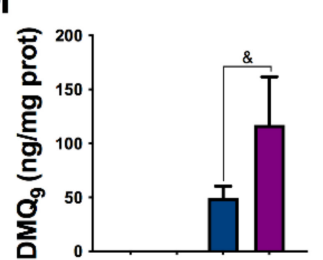

$\mathbf{R}$

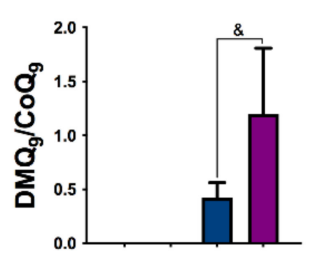

$\mathbf{N}$

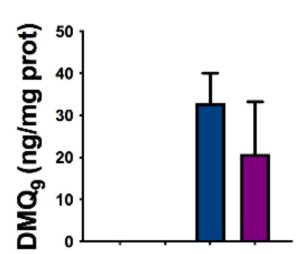

S

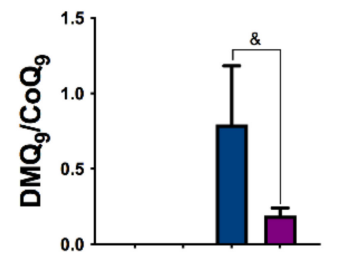

$\mathbf{T}$
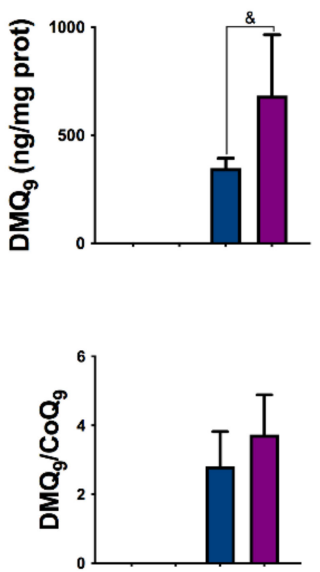

U
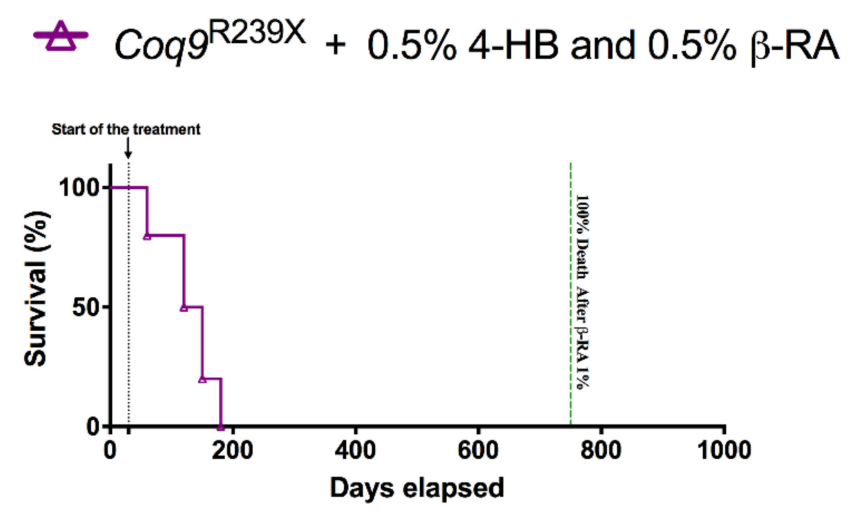

Figure 4. Co-administration of 4-HB suppressed the effects of the $\beta$-RA treatment in the $\operatorname{Cog} 9^{+/+}$and $\operatorname{Cog} 9^{R 239 X}$ mice. (A-E) Levels of $\mathrm{CoQ}_{9}$ in the brain (A), kidneys (B), liver (C), skeletal muscle (D), and heart (E) from the $\operatorname{Coq} 9^{+/+}$mice, Coq9 $9^{+/+}$ mice given the $0.5 \% 4-\mathrm{HB}+0.5 \% \beta-\mathrm{RA}$ treatment, $\operatorname{Coq} 9^{R 239 \mathrm{X}}$ mice, and $\operatorname{Cog} 9^{R 239 \mathrm{X}}$ mice given the $0.5 \% 4-\mathrm{HB}+0.5 \% \beta-\mathrm{RA}$ treatment. (F-J) Levels of $\mathrm{CoQ}_{10}$ in the brain $(\mathbf{F})$, kidneys $(\mathbf{G})$, liver $(\mathbf{H})$, skeletal muscle $(\mathbf{I})$, and heart $(\mathbf{J})$ from the $\mathrm{Coq}^{+/+}$ mice, $\mathrm{Cog}^{+/ /+}$mice given the $0.5 \%$ 4- $\mathrm{HB}+0.5 \% \beta$-RA treatment, $\operatorname{Coq} 9^{R 239 \mathrm{X}}$ mice, and $\operatorname{Cog} 9^{R 239 \mathrm{X}}$ mice given the $0.5 \% 4-\mathrm{HB}+$ $0.5 \% \beta$-RA treatment. (K-O) Levels of $\mathrm{DMQ}_{9}$ in the brain $(\mathbf{K})$, kidneys $(\mathbf{L})$, liver $(\mathbf{M})$, skeletal muscle $(\mathbf{N})$, and heart $(\mathbf{O})$ from 
the $\operatorname{Coq} 9^{+/+}$mice, $\operatorname{Coq} 9^{+/+}$mice given the $0.5 \% 4-\mathrm{HB}+0.5 \% \beta-\mathrm{RA}$ treatment, $\operatorname{Coq} 9^{R 239 \mathrm{X}}$ mice, and Coq $9^{R 239 \mathrm{X}}$ mice given the $0.5 \% 4-\mathrm{HB}+0.5 \% \beta-\mathrm{RA}$ treatment. $(\mathbf{P}-\mathbf{T})$ The $\mathrm{DMQ}_{9} / \mathrm{CoQ}_{9}$ ratio in the brain $(\mathbf{P})$, kidneys $(\mathbf{Q})$, liver $(\mathbf{R})$, skeletal muscle (S), and heart (T) from the Coq9 ${ }^{+/+}$mice, $\operatorname{Coq} 9^{+/+}$mice given the $0.5 \% 4-\mathrm{HB}+0.5 \% \beta-\mathrm{RA}$ treatment, $\operatorname{Coq} 9^{R 239 \mathrm{X}}$ mice, and Coq $9^{R 239 X}$ mice given the $0.5 \% 4-\mathrm{HB}+0.5 \% \beta$-RA treatment. (U) Survival curve of the Coq $9^{R 239 X}$ mice given the $0.5 \% 4-\mathrm{HB}$ $+0.5 \% \beta$-RA treatment. Tissues from mice at 3 months of age. Data are expressed as mean \pm SD. ${ }^{*} p<0.05,{ }^{* *} p<0.01$, ${ }^{* * *} p<0.001$, differences versus $\operatorname{Coq} 9^{+/+} .+p<0.05,++p<0.01,+++p<0.001$, differences versus $\operatorname{Coq} 9^{+/+}$after the $0.5 \% 4-\mathrm{HB}$ and $0.5 \% \beta$-RA treatment. \& $p<0.05, \& \& p<0.01$, differences versus Coq $9^{R 239 X}$. One-way ANOVA with Tukey's post hoc test or Mann-Whitney (nonparametric) test; $n=5-10$ for each group.

\subsection{A Metabolic Switch in Wild-Type Animals Contributed to the Effects of $\beta$-RA in Reducing WAT}

Since the interference of $\beta$-RA in CoQ metabolism in wild-type mice was very mild, the profound reduction in WAT was not likely attributed to CoQ metabolism. Thus, we investigated whether $\beta$-RA can target other mitochondrial pathways by performing quantitative proteomics on mitochondrial fractions of kidneys from wild-type mice treated with $1 \% \beta$-RA for only two months and compare the results to those of kidneys from the untreated wild-type mice (Data File S1). We chose a higher dose to ensure that the effects of the $\beta$-RA supplementation were evident. Furthermore, the analysis was done in the kidneys because this tissue maintained the highest levels of $\beta$-RA after the supplementation. In the kidneys of the wild-type mice treated with $\beta$-RA compared to kidneys of the untreated wild-type mice, 442 mitochondrial proteins were differentially expressed (Data File S2), with 300 proteins being overexpressed and 142 proteins being underexpressed. Canonical metabolic analysis showed enrichment (top 10) of the pathways of fatty acid $\beta$-oxidation, acetyl-CoA biosynthesis, the tricarboxylic acid (TCA) cycle, and the 2-ketoglutarate dehydrogenase complex, as well as enrichment of the related branchedchain $\alpha$-keto acid dehydrogenase complex (Figure 5A). Importantly, the prediction z-score revealed an inhibition of fatty acid $\beta$-oxidation and activation of acetyl-CoA biosynthesis and the TCA cycle (Figure 5A), which was consistent with the changes found in the levels of key proteins in these pathways (Figure $5 \mathrm{~B}$ ). Western blotting for the proteins ALDH1B1, GSK3 $\beta$, EHHADH, and ACADM from the mice fed at 1 or $0.33 \% \beta$-RA in the diet (Figure 5C,D) validated these findings in the kidneys. Taken together, the results of the mitochondrial proteome analysis suggested that $\beta$-RA treatment stimulates the production and use of acetyl-CoA in the kidneys while repressing fatty acid $\beta$-oxidation in the kidneys (Figure 5E). Thus, we hypothesized that $\beta$-RA supplementation induces glycolysis at the expense of fatty acid $\beta$-oxidation. For this, lipolysis may induce an increase in glycerol-3-P (G3P), which may stimulate glycolysis to provide the substrate for acetyl-CoA biosynthesis. Accordingly, the activities of the glycolytic enzymes phosphofructokinase (PFK) and pyruvate kinase (PK) were partially increased with the $\beta$-RA treatment (Figure $5 \mathrm{~F}, \mathrm{G}$ ). Moreover, G3P were increased with the $\beta$-RA treatment (Figure $5 \mathrm{H}$ ), while the levels of $\beta$-hydroxybutyrate (BHB) showed a notable but statistically insignificant increase with the $\beta$-RA treatment (Figure 5I). 
A

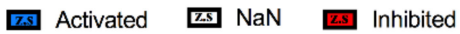

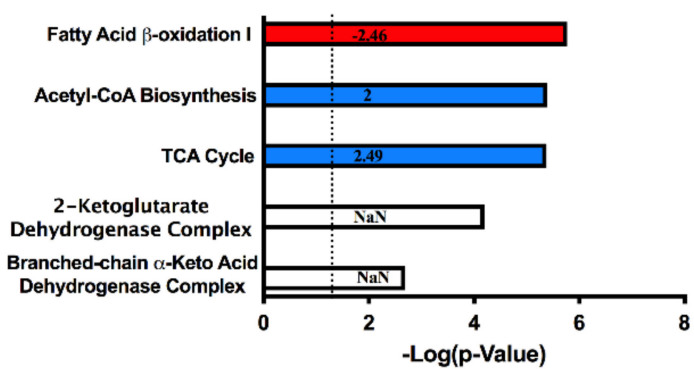

C
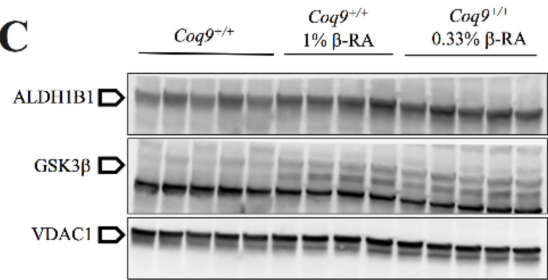

B

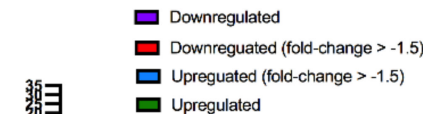

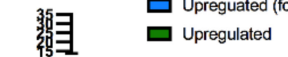

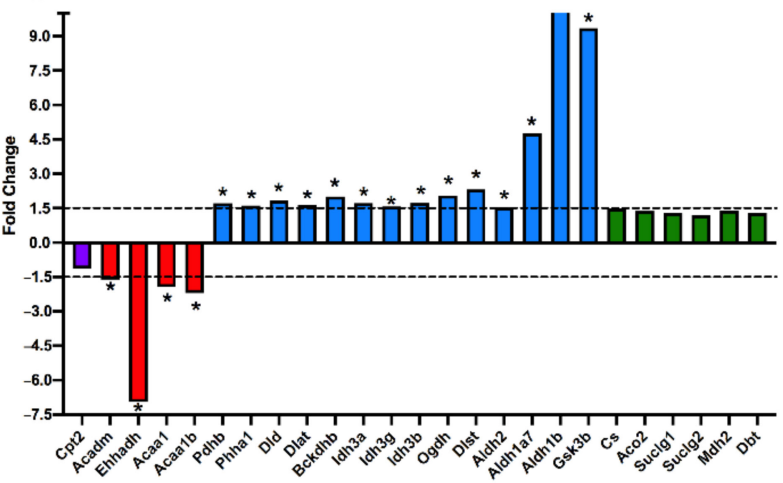

Proteins

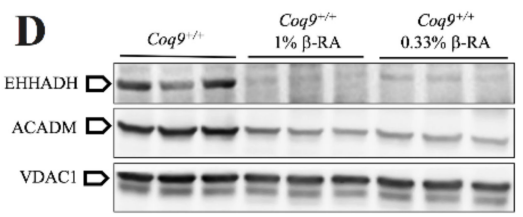

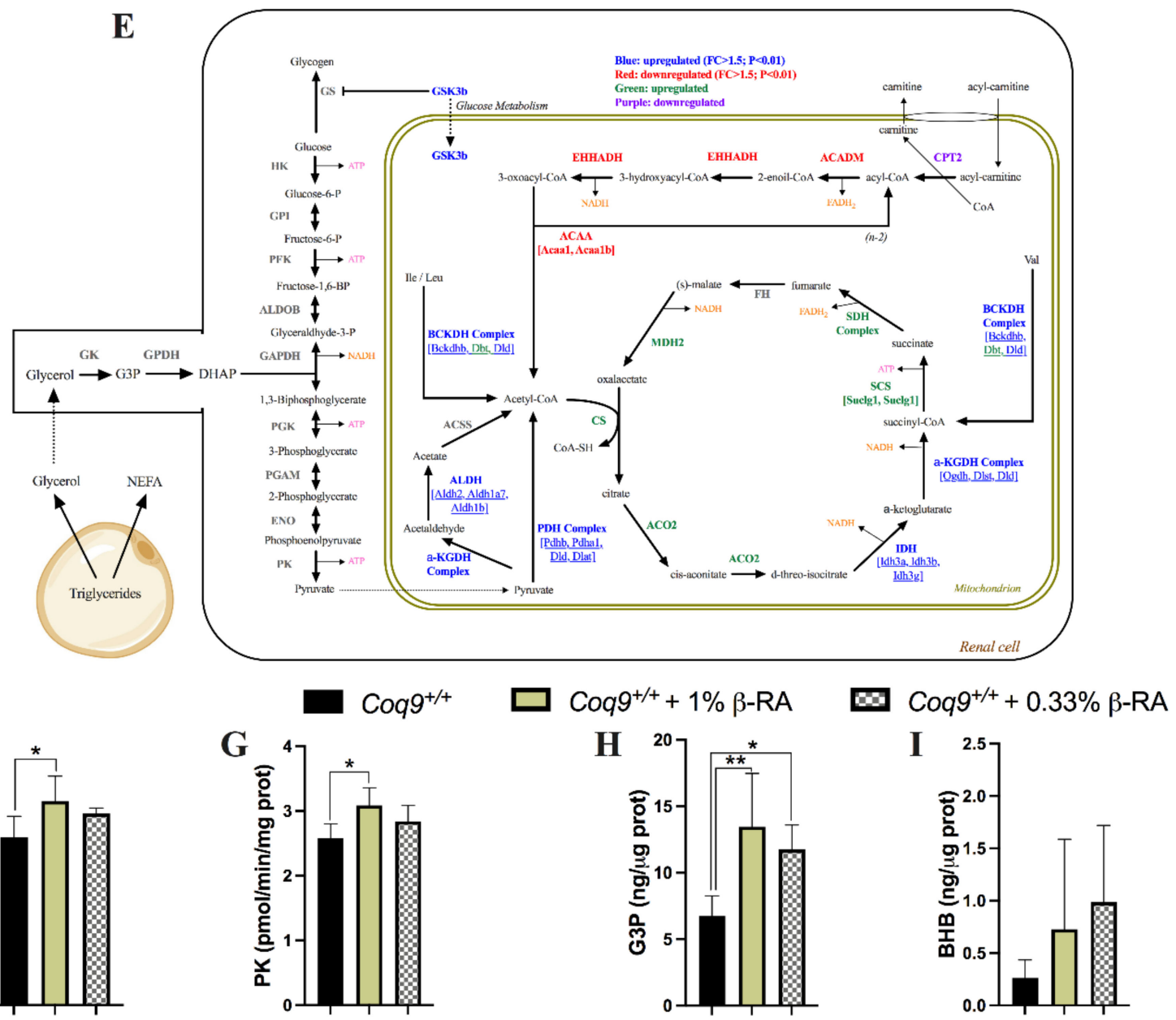

Figure 5. Adaptation of the mitochondrial proteome to the treatment with $\beta-R A$ in the kidneys of the Cog $9^{+/+}$mice. (A) Top enriched metabolic canonical pathways in the renal mitochondrial proteome from the Coq $9^{+/+}$mice after two months of $1 \% \beta$-RA supplementation. Dotted line: Adjusted $p=0.05$. Blue signifies that the category was expected to be activated according to the $z$-score; red signifies that the category was expected to be inhibited according to the $z$-score. (B) Fold change 
(treated/untreated) of the proteins involved in the identified enriched metabolic canonical pathways in the renal mitochondrial proteome. Purple signifies proteins that were downregulated; red signifies proteins that were downregulated with a fold change $>1.5$; blue signifies proteins that were upregulated with a fold change $>1.5$; green signifies proteins that were upregulated. ${ }^{*} p<0.05$. Mitochondrial proteomics was performed in isolated mitochondria. (C,D) Western blot of some key proteins identified in the proteomics analysis to validate the changes observed with the treatment of $\beta$-RA. The validation was performed with the treatment of $\beta$-RA at $1 \%$ and extended to the treatment of $\beta$-RA at $0.33 \%$. The selected proteins were ALDH1B1, GS3K $\beta, E H H A D H$, and ACADM. VDAC1 was used as a loading control. The experiments were performed in tissue homogenate. (E) Schematic figure of the most important changes in the mitochondrial proteomes from the kidneys of the $\operatorname{Coq} 9^{+/+}$mice after the $\beta$-RA treatment. (F,G) Activities of the glycolytic enzymes phosphofructokinase $(\mathrm{PFK})(\mathbf{F})$ and pyruvate kinase (PK) (G) in the kidneys of the Coq $9^{+/+}$mice treated with $\beta$-RA at 1 and $0.33 \%$. (H,I) Levels of glycerol-3-phosphate (G3P) (H) and $\beta$-hydroxybutyrate (BHP) (I) in the kidneys of the Coq9 ${ }^{+/+}$mice treated with $\beta$-RA at 1 and $0.33 \%$. Tissues from mice at 3 months of age. Data are expressed as mean \pm SD. ${ }^{*} p<0.05,{ }^{* *} p<0.01$, differences versus $\mathrm{Co} 9^{+/+}$. One-way ANOVA with Tukey's post hoc test or Mann-Whitney (nonparametric) test; $n=5-7$ for each group.

We performed similar analyses in the liver and skeletal muscle, which are two relevant tissues in the regulation of systemic energy metabolism, to check whether this metabolic switch was a common phenomenon. The levels of the proteins ALDH1B1, GSK3 $\beta$, EHHADH, and ACADM in the liver and skeletal muscle did not change like the changes observed in the kidneys (Figures 6A-F and S7A-F). However, PFK activity increased with the $\beta$-RA treatment in both tissues (Figures 6G and S7G), suggesting the activation of glycolysis despite a lack of change of PK activity from the treatment (Figures $6 \mathrm{H}$ and S7H). Moreover, G3P increased in the liver with the treatment of $1 \% \beta-\mathrm{RA}$, although these levels did not change at the low dose nor in the skeletal muscle with both doses (Figures 6I and S7I). In the liver, the levels of BHB showed an observable but statistically insignificant increase with the $\beta$-RA treatment (Figure 6J). The levels of Fgf21, which is a secretory endocrine factor that can affect systemic glucose and lipid metabolism [31], trended upward with the $\beta$-RA treatment (Figure 6K). An increase in BHB levels was also observed in the blood plasma with the treatment of $1 \% \beta$-RA (Figure $6 \mathrm{~L}$ ). However, the levels of non-esterified fatty acids (NEFA), which are products of lipolysis, were similar in the treated and untreated animals (Figure 6M). Furthermore, the levels of glucagon, insulin, and the insulin/glucagon ratio were similar in the treated and untreated animals, which most likely reflected a homeostatic status with the chronic administration of $\beta$-RA (Figure $6 \mathrm{~N}-\mathrm{P}$ ). These results suggest that metabolism in the kidneys and, to a lesser extent, the liver contributed to the reduced WAT that was induced by $\beta$-RA in wild-type animals. 


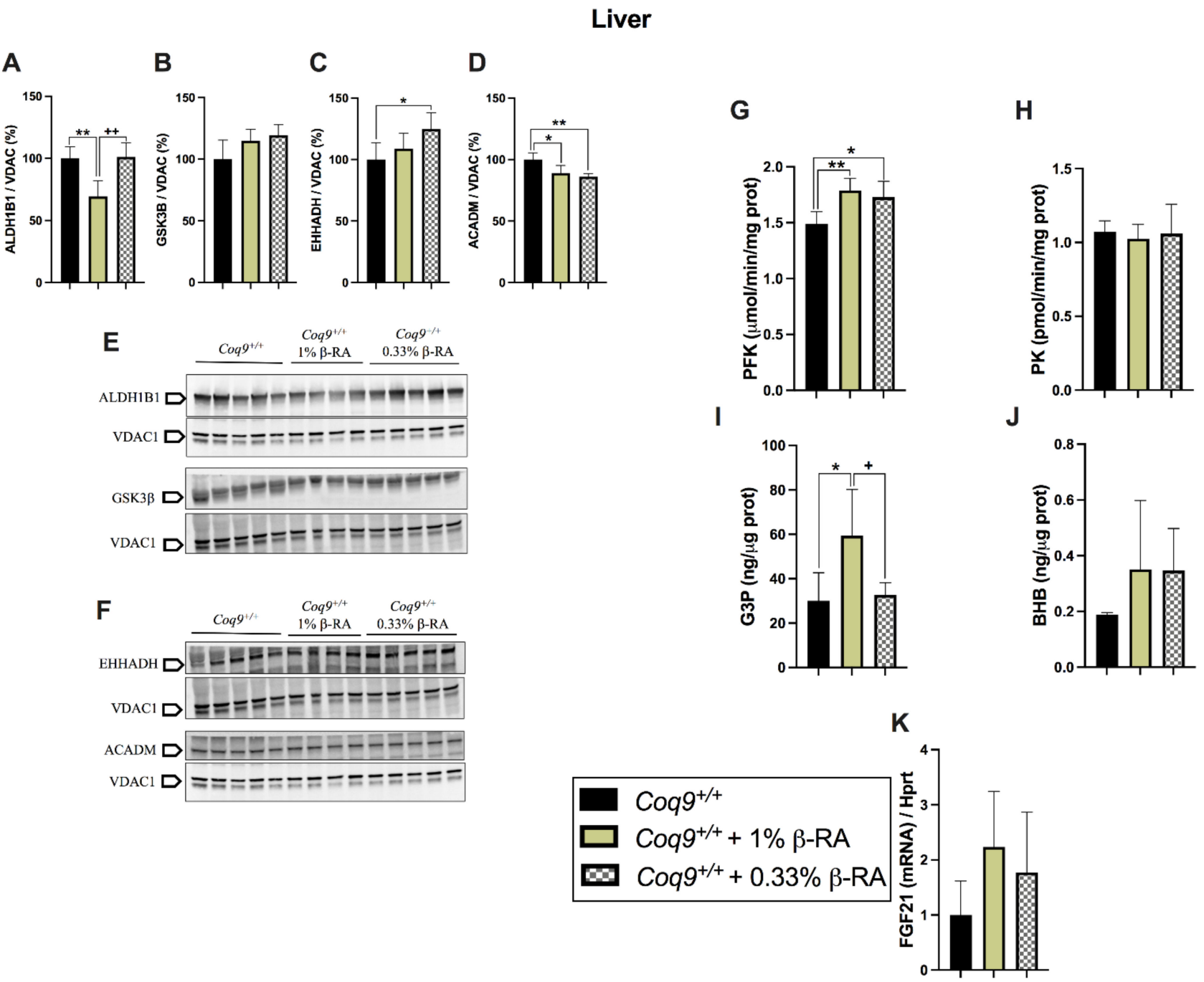

Plasma

L

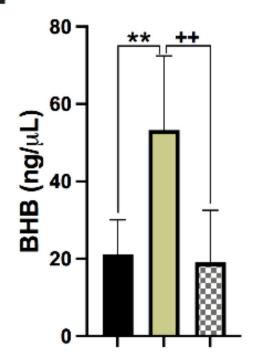

M

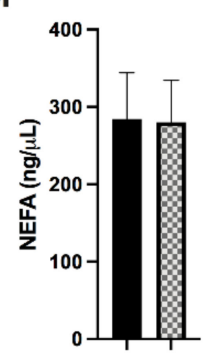

N

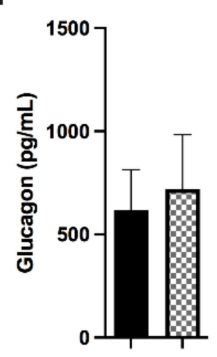

0

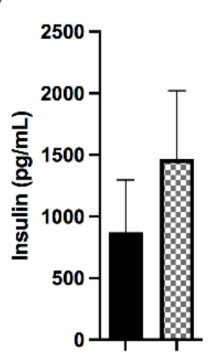

$\mathbf{P}$

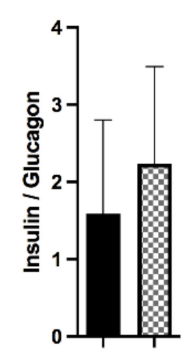

Figure 6. Metabolic characterization of liver and plasma after the treatment with $\beta$-RA in the Cog $9^{+/+}$mice. (A-F) Levels of the proteins ALDH1B1 $(\mathbf{A}, \mathbf{E}), \operatorname{GSK} 3 \beta(\mathbf{B}, \mathbf{E}), \operatorname{EHHADH}(\mathbf{C}, \mathbf{F})$, and ACADM $(\mathbf{D}, \mathbf{F})$ in the liver of the $\mathrm{Co} 9^{+/+}$mice treated with $\beta$-RA at 1 and $0.33 \%$. VDAC1 was used as a loading control. The experiments were performed in tissue homogenate. (G-J) Activities of the glycolytic enzymes phosphofructokinase (PFK) (G) and pyruvate kinase (PK) (H) in the liver; levels of glycerol-3-phosphate (G3P) in the liver (I); levels of $\beta$-hydroxybutyrate (BHP) in the liver (J). (K) Levels of the FGF21 mRNA in the liver. (L-P) Levels of $\beta$-hydroxybutyrate (BHP) (L), non-esterified fatty acids (NEFA) (M), glucagon (N), and insulin (O) in the plasma of the $\mathrm{Cog} 9^{+/+}$mice treated with $\beta$-RA; glucagon/insulin ratio $(\mathbf{P})$ in the plasma of the $\mathrm{Cog}^{9^{+/+}}$ mice treated with $\beta$-RA. Tissues from mice at 3 months of age. Data are expressed as mean $\pm \mathrm{SD} .{ }^{*} p<0.05,{ }^{* *} p<0.01$, differences versus $\operatorname{Cog}^{+/+} .+p<0.05,++p<0.01$, differences versus $\operatorname{Co} 9^{+/+}$after $1 \% \beta$-RA treatment. One-way ANOVA with Tukey's post hoc test or Mann-Whitney (nonparametric) test; $n=5-7$ for each group. 


\section{4. $\beta$-RA Directly Inhibited Adipogenesis}

While the metabolic switch in the kidneys and, to a lesser extent, the liver may contribute to the utilization of energetic substrates that prevent the accumulation of WAT, we also wondered whether $\beta$-RA directly affects adipocytes. This is important because mitochondrial metabolism was related to the inhibition of preadipocytes proliferation $[32,33]$. Thus, we treated 3T3-L1 preadipocytes with $\beta$-RA. In proliferative conditions, $\beta$-RA decreased cell proliferation (Figure 7A,D), most likely due to an increase in p27 (Figure 7B), which is a protein that inhibits the cell cycle progression at G1 [34,35]. We also observed a decrease in CYCA2, which is a protein that promotes the division of the cells [35] (Figure 7B). These changes in p27 and CYCA2 were not observed in differentiated 3T3-L1 cells (Figure 7C) nor in $\mathrm{C} 2 \mathrm{C} 12$ myoblasts under both proliferative and differentiative conditions (Figure S8), indicating a specific cell-type effect. Consistently, the 3T3-L1 cells treated with $\beta$-RA produced less fat (Figure 7E,F), which was a phenomenon that may have been mediated by the decrease in PPAR $\gamma$ levels (Figure 7G) and the upward trend of PPAR $\delta$ levels (Figure $7 \mathrm{H}$ ), which are two receptors that regulate adipogenesis [36,37]. The decreased levels of $\mathrm{CoQ}_{9}$ (Figure 7I,J) due to the competitive inhibition of $\mathrm{CoQ}$ biosynthesis induced by $\beta-R A$ in the control cells, which is a fact that was previously reported [1,38], could also contribute to the decreased proliferation and fat production of 3T3-L1 cells [32,39].

Because other HBAs, e.g., salicylic acid or vanillic acid, can activate AMPK [40,41], which is an enzyme that plays a key role in cellular energy homeostasis [42,43], we investigated whether the observed effects of $\beta$-RA in WAT were due to the activation of AMPK through its phosphorylation. Thus, we quantified the levels of AMPK and $p$-AMPK, as well as two of its target proteins, ULK1/p-ULK1 and ACC/p-ACC, in the WAT of wild-type mice at 18 months of age. Both the phosphorylated and unphosphorylated forms of the three proteins were increased, although the p-AMPK/AMPK, p-ULK1/ULK, and $\mathrm{p}-\mathrm{ACC} / \mathrm{ACC}$ ratios were similar in the untreated and treated animals (Figure S9A-C), suggesting that AMPK was not a direct target of $\beta$-RA. Moreover, the 3T3-L1 cells treated with $\beta$-RA did not experience changes in the p-AMPK/AMPK ratio, with p-AMPK being almost undetectable in both the treated and untreated cells (Figure S9D,E). 


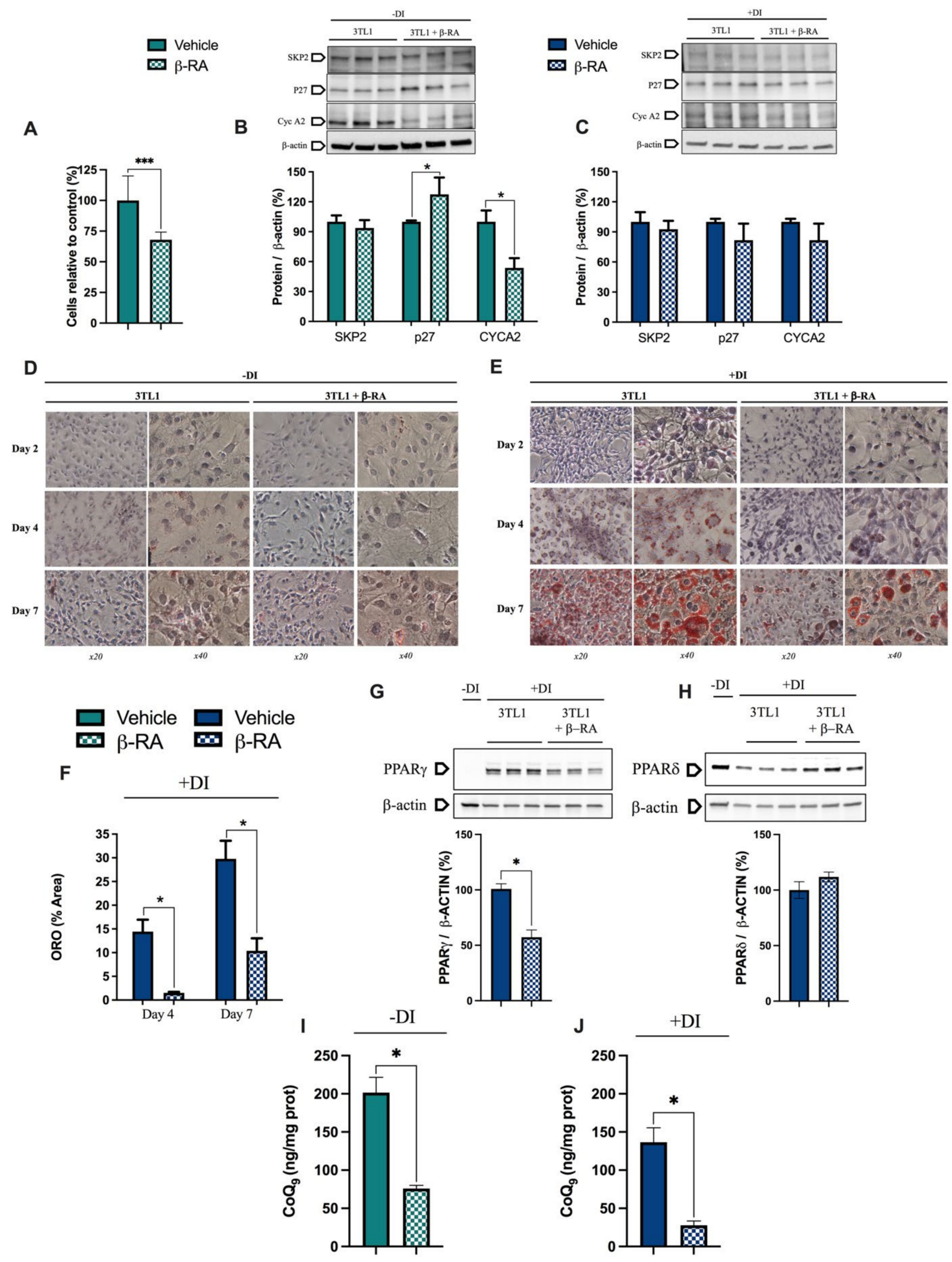

Figure 7. Direct effects of $\beta$-RA on adipogenesis. (A) Percentage of 3TL1 cells after seven days of treatment with $1 \mathrm{mM}$ $\beta$-RA relative to the number of untreated 3TL1 cells. Cells cultured in proliferative conditions. (B) Levels of the proteins SKP2, p27, and CYCA2, which were involved in the control of the cell cycle. The 3TL1 cells were treated for seven days with $1 \mathrm{mM} \beta$-RA in proliferative conditions. (C) Levels of the proteins SKP2, p27, and CYCA2, which were involved in cell cycle control. The 3TL1 cells were treated for seven days with $1 \mathrm{mM} \beta$-RA in differentiative conditions. (D,E) Oil Red O staining 
in 3TL1 cells cultured under proliferative (D) and proliferative + differentiative (F) conditions. The 3TL1 cells were treated with $1 \mathrm{mM} \beta$-RA from day 0 in both conditions and the stains were performed on three different days $(2,4$, and 7$)$. (F) Percentage of the area corresponding to the Oil Red O stains in the 3TL1 cells in differentiative conditions after days 4 and 7 of treatment with $1 \mathrm{mM} \beta-\mathrm{RA}$. (G,H) Levels of PPAR $\gamma$ and PPAR $\delta$ in the $3 \mathrm{TL} 1$ cells cultured in proliferative + differentiative (F) conditions and treated with $1 \mathrm{mM} \beta$-RA. The results in non-differentiated cells are shown in line one as the negative control. (I,J) Levels of $\mathrm{CoQ}_{9}$ in the 3TL1 cells cultured in proliferative conditions (I) and differentiative conditions (J) and treated with $1 \mathrm{mM} \beta$-RA. Data are expressed as mean $\pm \mathrm{SD} .{ }^{*} p<0.05,{ }^{* * *} p<0.001$, differences versus untreated cells (Mann-Whitney (nonparametric) test; $n=6$ for each group).

\section{Discussion}

$\beta-\mathrm{RA}$ is an HBA that shows powerful therapeutic benefits in CoQ deficiency mouse models caused by mutations in $\operatorname{Coq} 6, \operatorname{Coq} 7, \operatorname{Coq} 8 b$, or $\operatorname{Coq} 9[21,22,24,25]$. Those studies administered high doses of oral $\beta$-RA, but the mechanisms have not been clearly elucidated in podocyte-specific Coq6 or Coq8b knockout mice [24,25]. Moreover, chronic $\beta$-RA supplementation maintains a lower body weight in wild-type mice than untreated mice [21], but the causes and mechanisms of this effect were completely unknown. In our current work, we demonstrated that the therapeutic mechanism of $\beta-R A$ in Coq9 ${ }^{R 239 X}$ mice was based on the capability of this molecule to enter the CoQ biosynthetic pathway and compete with $4-\mathrm{HB}$, resulting in a reduction of the levels of DMQ, an intermediate metabolite that is detrimental for mitochondrial function [44]. Moreover, our study revealed that $\beta$-RA prevented the accumulation of WAT during animal development and aging, thus preventing age-related hepatic steatosis. This powerful effect was due to an inhibition of preadipocyte proliferation and fat production, as well as the stimulation of lipolysis, gluconeogenesis, and glucose and acetyl-CoA utilization, mainly in the kidneys.

The fundamental rationale for the treatment with $\beta$-RA in primary CoQ deficiency is the induction of a bypass effect since $\beta$-RA has the hydroxyl group that is normally incorporated into the benzoquinone ring by the hydroxylase COQ7. Because COQ9 is essential for the stability and function of COQ7 [6], defects in either Coq7 or Coq9 are susceptible to be effectively treated by $\beta$-RA $[1,21-23,45]$. Surprisingly, $\beta$-RA treatment was also successful in podocyte-specific Coq6 or Coq8b knockout mice, yet the mechanisms in those cases were apparently not related to a bypass effect, suggesting that the $\beta$-RA may induce additional therapeutic mechanisms. However, our results confirmed that the therapeutic mechanism of $\beta$-RA in the $\operatorname{Coq} 9^{R 239 X}$ mice was due to its action in CoQ metabolism, as demonstrated by (1) the decrease in the levels of DMQ, with the effect being more intense in the kidneys (the tissue that accumulated more $\beta-\mathrm{RA}$ ), and (2) the suppression of the therapeutic effect of $\beta-\mathrm{RA}$ due to the co-administration of $4-\mathrm{HB}$, which attenuated the decrease of $\mathrm{DMQ}_{9}$, thus supporting the theory of competition between the molecules when trying to enter the CoQ biosynthetic pathway in vivo [38]. The results obtained with the co-administration of $4 \mathrm{HB}$ and $\beta-\mathrm{RA}$ also suggest that the $\mathrm{K}_{\mathrm{M}}$ for $\beta-\mathrm{RA}$ was higher than the $\mathrm{K}_{\mathrm{M}}$ for 4-HB in the prenylation reaction catalyzed by COQ2 [22,38]. Moreover, the therapeutic effects observed in this study were achieved with a third of the dose that was previously used [22]. Thus, the effects in this study were also similar to the results published in the Coq7 conditional KO mice [23] despite the phenotypes of both models being substantially different $[6,21]$. This is important because animal studies that use lower doses of a drug could potentially be translatable to the human situation, decreasing the cost of the treatment and being more feasible regarding its administration, especially in the pediatric population. However, our results in the Coq $9^{R 239 X}$ mice showed that $\beta$-RA had limitations regarding inducing an increase in the levels of CoQ, suggesting that the co-supplementation of $\beta-\mathrm{RA}$ and $\mathrm{CoQ}_{10}$ could result in improved therapeutic outcomes [46]. Moreover, $\beta-\mathrm{RA}$ is not able to be modified the DMQ/CoQ ratio in the brain, suggesting that $\beta$-RA may have additional mechanisms that reduce the astrogliosis or that the effects on CoQ metabolism are happening in specific cells types or areas in the brain.

In wild-type animals, chronic $\beta$-RA supplementation prevented the accumulation of WAT. The in vitro experiments in this study demonstrated that $\beta$-RA inhibited preadipocytes 
proliferation, which is a result that was also achieved by other phenolic acids [47,48], including $p$-coumaric [47], which was reported to serve as a benzoquinone precursor for CoQ biosynthesis in humans and mice [49]. Whether the alteration on CoQ biosynthesis that was induced by $\beta-R A$, i.e., the decrease in CoQ levels or the mild accumulation of DMQ, may contribute to the accumulation of WAT remains to be elucidated. The antiproliferative effect of $\beta$-RA in preadipocytes induces the downregulation of PPAR $\gamma$, which seems to be critical for the suppression of adipocyte differentiation and the development of mature adipocytes [50]. Consequently, $\beta$-RA may act by preventing WAT hyperplasia and hypertrophy, both of which contribute to avoiding overweight and obesity in children and adults [51-53].

In addition to the direct effects of $\beta$-RA in adipocytes, in vivo experiments utilizing hypotheses that were generated by proteomic profiling, and following these observations up with focused validation experiments, showed a tissue metabolic switch, mainly in the kidneys. This tissue could account for up to $40 \%$ of the overall gluconeogenesis of the body under certain conditions, e.g., the post-absorptive phase [54,55], during which glycerol is one of the gluconeogenic renal precursors [54]. Although renal gluconeogenesis mainly serves to produce glucose only for its own utilization in the kidneys, this metabolic process can also participate in the regulation of systemic glucose metabolism [55]. Therefore, our results suggest that the $\beta$-RA induces renal gluconeogenesis from glycerol, and the resulting glucose is used in glycolysis to produce pyruvate and then acetyl-CoA, which is ultimately funneled into the TCA cycle. Acetyl-CoA may not only be produced through the classical pathway but also through an alternative pathway that involves $\alpha$-ketoglutarate dehydrogenase and aldehyde dehydrogenase and uses acetaldehyde as an intermediate metabolite [56]. Interestingly, the production and use of acetyl-CoA in mitochondria were postulated as a metabolic signal of survival in organisms [57], which is consistent with a reduction in the WAT content [57,58], the stimulation of ketogenesis [57,59], the limitation of fatty acid synthesis, and the prevention of hepatic steatosis [57-59]. Nevertheless, it is unclear whether the metabolic effects in the kidneys and, to a lesser extent, in the liver are due to $\beta$-RA itself or whether they are the consequences of having a low amount of WAT. This second option could explain the downregulation of fatty acid $\beta$-oxidation in the kidneys and the subsequent preference for glucose metabolism. A potential regulator for all these metabolic changes is GSK3 $\beta$, which is highly increased in the mitochondria of the treated wild-type animals. GSK $3 \beta$ regulates a variety of cellular processes, including glucose metabolism. In fact, its upregulation was associated with an amelioration of diabetes-induced kidney injury [60]. Consequently, these metabolic adaptations in the kidneys in response to chronic supplementation of $\beta$-RA could explain, at least in part, the positive therapeutic outcomes achieved in the podocyte-specific Coq6 or Coq8b knockout mice $[24,25]$ and open the potential application of $\beta$-RA in treating other renal metabolic diseases.

To conclude, the results reported here demonstrate that chronic supplementation with $\beta$-RA in mice induces different metabolic effects with relevant therapeutic implications for the treatment of primary CoQ deficiency and the prevention of age-related overweight and associated hepatic steatosis. The first application is based on the ability of $\beta$-RA to enter the CoQ biosynthetic pathway, compete with a lower affinity with the natural substrate 4-HB, and, consequently, reduce the levels of DMQ in cases of defects in Coq9 or Coq7. The second application is based on a combination of direct influences over WAT, ultimately preventing the hyperplasia and hypertrophy of adipocytes, and to indirect systemic mechanisms, mainly by the adaptations of renal metabolism. Nevertheless, this study has some limitations: (1) although $\beta$-RA can prevent the accumulation of WAT during aging, it is unknown whether it can reduce WAT in already obese animals; (2) although this long-term study showed convincing therapeutic actions of $\beta-R A$, the effects of $\beta$-RA administration should be evaluated in mice with different genetic backgrounds and models of both diet-induced obesity and genetic-induced obesity; and (3) a minimal effective dose and potential dose-dependent specific effects must be defined for both 
therapeutic applications. Nevertheless, the data gathered in the present work are relevant for the future translation of the treatment with $\beta$-RA into the clinic, especially considering that we have shown the effects of the long-term administration of $\beta$-RA in a mouse model of age-related overweight and mitochondrial encephalopathy due to CoQ deficiency.

Supplementary Materials: The following are available online at https:/ /www.mdpi.com/article/10 $.3390 /$ biomedicines $9101457 / \mathrm{s} 1$, Table S1: Markers of hepatic and renal function in the plasma and urine from $\mathrm{Cog}^{+/+}$mice and $\mathrm{Cog}^{+/+}$mice under $0.33 \%$ of $\beta$-RA supplementation, Figure S1: Muscle Strength, Figure S2: Morphological and histological features from Coq $9^{+/+}, \operatorname{Cog}^{+/+}$mice under 0.33\% of $\beta$-RA treatment, $\operatorname{Cog} 9^{R 239 X}$ and $\operatorname{Cog} 9^{R 239 X}$ mice under $0.33 \%$ of $\beta$-RA treatment at 3 and 18 Month of age, Figure S3: Representative chromatographs showing the peaks of $\mathrm{Co}_{9}$ and $\mathrm{DMQ}_{9}$ in the kidneys, Figure S4: CoQ metabolism and mitochondrial function in the heart from $\mathrm{Cog}^{+/+}$mice, $\mathrm{Cog}^{+/+}$mice under the supplementation with $0.33 \% \beta-\mathrm{RA}, \operatorname{Cog} 9^{R 239 \mathrm{X}}$ mice and $\operatorname{Coq} 9^{R 239 \mathrm{X}}$ mice under the supplementation with $0.33 \% \beta-$ RA, Figure S5: CoQ levels in WAT from Coq $9^{+/+}$mice and $\operatorname{Cog}^{+/+}$mice under the supplementation with $0.33 \% \beta$-RA, Figure S6: Mitochondrial oxygen consumption rate (represented as State 3o, in the presence of ADP and substrates) in brain (A) and kidneys (B), Figure S7: Metabolic characterization of the skeletal muscle after the treatment with $\beta$-RA in $\mathrm{Cog}^{+/+}$mice, Figure S8: Effects of $\beta$-RA in the proliferation and differentiation of C2C12 myoblasts, Figure S9: Analysis of the AMPK pathway in white adipose tissues and 3TL1 cells, Movie S1: Video that shows the difference between a Coq9 ${ }^{+/+}$mouse and a Coq9 ${ }^{R 239 X}$ mouse under $0.33 \% \beta$-RA supplementation, both males at 20 months of age. Both animals have a healthy appearance, although the treated $\operatorname{Cog} 9^{R 239 X}$ mouse is smaller, as previously reported, Movie S2: Video that shows the difference between a $\operatorname{Cog} 9^{R 239 X}$ mouse and a $\operatorname{Coq} 9^{R 239 X}$ mouse under $0.33 \%$ $\beta$-RA treatment, both males at 3 months of age. The untreated $\operatorname{Cog} 9^{R 239 X}$ mouse has developed a paralysis in the legs, although the treated $\operatorname{Coq}^{R 239 X}$ mouse has a healthy appearance, Movie S3: Video that shows a Coq9 ${ }^{+/+}$mouse and a $\operatorname{Cog}^{+/+}$mouse under $0.33 \% \beta$-RA supplementation, both males at 20 months of age. The appearance of both animals is similar. Data File S1: Quantitative proteomics on mitochondrial fractions of kidneys from wild-type mice treated with $1 \% \beta$-RA for only two months and compare the results to those of kidneys from the untreated wild-type mice, Data File S2: In the kidneys of the wild-type mice treated with $\beta$-RA compared to kidneys of the untreated wild-type mice, 442 mitochondrial proteins were differentially expressed.

Author Contributions: A.H.-G. led the study, developed the phenotypic and survival assay and the body weight measurements; conducted the tests to assess the mitochondrial bioenergetics, Western blot analyses, enzymatic assays, cell culture experiments, UHPLC EC and MS analysis, IPA analyses; analyzed the results; designed the figures; and wrote the manuscript. E.B.-C. contributed to the mitochondrial assays, Western blot analyses, qPCR analyses, enzymatic assays, the management of the mouse colony, the rotarod test, phenotyping, and cell culture experiments. M.E.D.-C. performed the morphological analyses. P.G.-G. contributed to the mitochondrial assays, proteomics experiments, and the management of the mouse colony. R.Z.C. supervised the proteomics experiments and analyses. D.A.-C. contributed to the discussions. L.C.L. conceived the idea for the project, supervised the experiments, and edited the manuscript. The results shown in this article constituted a section of A.H.-G.'s doctoral thesis at the University of Granada. All authors have read and agreed to the published version of the manuscript.

Funding: This work was supported by grants from Ministerio de Ciencia e Innovación, Spain, and the ERDF (grant number RTI2018-093503-B-100); from the Muscular Dystrophy Association (MDA602322); from the Junta de Andalucía (grant number P20_00134); from the University of Granada (grant reference "UNETE," UCE-PP2017-06); and by EPIC-XS, project number 823839, funded by the Horizon 2020 program of the European Union. P.G.-G. is a "FPU fellow" from the Ministerio de Universidades, Spain. M.E.D.-C. is supported by the Muscular Dystrophy Association. E.B.-C. is supported by the Junta de Andalucía. A.H.-G. was partially supported by the "FPU program" and the research program from the University of Granada.

Data Availability Statement: The mass spectrometry proteomics data were deposited to the ProteomeXchange (http:/ / www.proteomexchange.org/ accessed on 1 April 2020). Consortium via the PRIDE partner repository with the dataset identifier PXD018311 (1 April 2020). 
Acknowledgments: We thank Seth Joel Drey for the English editing. We are grateful to Ana Fernandez (Universidad de Granada) for her technical support at the facilities of bioanalysis. We thank members of the Heck Lab for their support in analyzing the proteomics samples.

Conflicts of Interest: A.H.-G., M.E.D.-C., E.B.-C., P.G.-G. and L.C.L. are inventors on the patent application number P202031235.

\section{References}

1. Luna-Sanchez, M.; Diaz-Casado, E.; Barca, E.; Tejada, M.A.; Montilla-Garcia, A.; Cobos, E.J.; Escames, G.; Acuna-Castroviejo, D.; Quinzii, C.M.; Lopez, L.C. The clinical heterogeneity of coenzyme $\mathrm{Q}_{10}$ deficiency results from genotypic differences in the Coq9 gene. EMBO Mol. Med. 2015, 7, 670-687. [CrossRef] [PubMed]

2. Desbats, M.A.; Morbidoni, V.; Silic-Benussi, M.; Doimo, M.; Ciminale, V.; Cassina, M.; Sacconi, S.; Hirano, M.; Basso, G.; Pierrel, F.; et al. The COQ2 genotype predicts the severity of coenzyme $Q_{10}$ deficiency. Hum. Mol. Genet. 2016, 25, 4256-4265. [CrossRef] [PubMed]

3. Quinzii, C.M.; Lopez, L.C.; Von-Moltke, J.; Naini, A.; Krishna, S.; Schuelke, M.; Salviati, L.; Navas, P.; DiMauro, S.; Hirano, M. Respiratory chain dysfunction and oxidative stress correlate with severity of primary CoQ ${ }_{10}$ deficiency. FASEB J. 2008, 22, 1874-1885. [CrossRef] [PubMed]

4. Quinzii, C.M.; Lopez, L.C.; Gilkerson, R.W.; Dorado, B.; Coku, J.; Naini, A.B.; Lagier-Tourenne, C.; Schuelke, M.; Salviati, L.; Carrozzo, R.; et al. Reactive oxygen species, oxidative stress, and cell death correlate with level of CoQ 10 deficiency. FASEB J. 2010, 24, 3733-3743. [CrossRef] [PubMed]

5. Lopez, L.C.; Quinzii, C.M.; Area, E.; Naini, A.; Rahman, S.; Schuelke, M.; Salviati, L.; DiMauro, S.; Hirano, M. Treatment of CoQ(10) deficient fibroblasts with ubiquinone, CoQ analogs, and vitamin C: Time- and compound-dependent effects. PLoS ONE 2010, 5, e11897. [CrossRef]

6. Garcia-Corzo, L.; Luna-Sanchez, M.; Doerrier, C.; Garcia, J.A.; Guaras, A.; Acin-Perez, R.; Bullejos-Peregrin, J.; Lopez, A.; Escames, G.; Enriquez, J.A.; et al. Dysfunctional Coq9 protein causes predominant encephalomyopathy associated with CoQ deficiency. Hum. Mol. Genet. 2013, 22, 1233-1248. [CrossRef]

7. Quinzii, C.M.; Garone, C.; Emmanuele, V.; Tadesse, S.; Krishna, S.; Dorado, B.; Hirano, M. Tissue-specific oxidative stress and loss of mitochondria in CoQ-deficient Pdss2 mutant mice. FASEB J. 2013, 27, 612-621. [CrossRef] [PubMed]

8. Duberley, K.E.; Abramov, A.Y.; Chalasani, A.; Heales, S.J.; Rahman, S.; Hargreaves, I.P. Human neuronal coenzyme Q(10) deficiency results in global loss of mitochondrial respiratory chain activity, increased mitochondrial oxidative stress and reversal of ATP synthase activity: Implications for pathogenesis and treatment. J. Inherit. Metab. Dis. 2013, 36, 63-73. [CrossRef]

9. Kleiner, G.; Barca, E.; Ziosi, M.; Emmanuele, V.; Xu, Y.; Hidalgo-Gutierrez, A.; Qiao, C.; Tadesse, S.; Area-Gomez, E.; Lopez, L.C.; et al. $\mathrm{CoQ}_{10}$ supplementation rescues nephrotic syndrome through normalization of H2S oxidation pathway. Biochim. Biophys. Acta Mol. Basis Dis. 2018, 1864, 3708-3722. [CrossRef] [PubMed]

10. Luna-Sanchez, M.; Hidalgo-Gutierrez, A.; Hildebrandt, T.M.; Chaves-Serrano, J.; Barriocanal-Casado, E.; Santos-Fandila, A.; Romero, M.; Sayed, R.K.; Duarte, J.; Prokisch, H.; et al. CoQ deficiency causes disruption of mitochondrial sulfide oxidation, a new pathomechanism associated with this syndrome. EMBO Mol. Med. 2017, 9, 78-95. [CrossRef] [PubMed]

11. Lopez-Martin, J.M.; Salviati, L.; Trevisson, E.; Montini, G.; DiMauro, S.; Quinzii, C.; Hirano, M.; Rodriguez-Hernandez, A.; Cordero, M.D.; Sanchez-Alcazar, J.A.; et al. Missense mutation of the COQ2 gene causes defects of bioenergetics and de novo pyrimidine synthesis. Hum. Mol. Genet. 2007, 16, 1091-1097. [CrossRef]

12. Mancuso, M.; Orsucci, D.; Volpi, L.; Calsolaro, V.; Siciliano, G. Coenzyme $\mathrm{Q}_{10}$ in neuromuscular and neurodegenerative disorders. Curr. Drug Targets 2010, 11, 111-121. [CrossRef]

13. Emmanuele, V.; Lopez, L.C.; Berardo, A.; Naini, A.; Tadesse, S.; Wen, B.; D’Agostino, E.; Solomon, M.; DiMauro, S.; Quinzii, C.; et al. Heterogeneity of coenzyme $Q_{10}$ deficiency: Patient study and literature review. Arch. Neurol. 2012, 69, 978-983. [CrossRef] [PubMed]

14. Quinzii, C.M.; Lopez, L.C.; Naini, A.; DiMauro, S.; Hirano, M. Human CoQ 10 deficiencies. Biofactors 2008, 32, 113-118. [CrossRef]

15. Turunen, M.; Olsson, J.; Dallner, G. Metabolism and function of coenzyme Q. Biochim. Biophys. Acta 2004, 1660, 171-199. [CrossRef]

16. Yubero, D.; Montero, R.; Martin, M.A.; Montoya, J.; Ribes, A.; Grazina, M.; Trevisson, E.; Rodriguez-Aguilera, J.C.; Hargreaves, I.P.; Salviati, L.; et al. Secondary coenzyme $\mathrm{Q}_{10}$ deficiencies in oxidative phosphorylation (OXPHOS) and non-OXPHOS disorders. Mitochondrion 2016, 30, 51-58. [CrossRef] [PubMed]

17. Fazakerley, D.J.; Chaudhuri, R.; Yang, P.; Maghzal, G.J.; Thomas, K.C.; Krycer, J.R.; Humphrey, S.J.; Parker, B.L.; Fisher-Wellman, K.H.; Meoli, C.C.; et al. Mitochondrial CoQ deficiency is a common driver of mitochondrial oxidants and insulin resistance. eLife 2018, 7, e32111. [CrossRef] [PubMed]

18. Bentinger, M.; Dallner, G.; Chojnacki, T.; Swiezewska, E. Distribution and breakdown of labeled coenzyme $\mathrm{Q}_{10}$ in rat. Free Radic. Biol. Med. 2003, 34, 563-575. [CrossRef]

19. Garcia-Corzo, L.; Luna-Sanchez, M.; Doerrier, C.; Ortiz, F.; Escames, G.; Acuna-Castroviejo, D.; Lopez, L.C. Ubiquinol-10 ameliorates mitochondrial encephalopathy associated with CoQ deficiency. Biochim. Biophys. Acta 2014, 1842, 893-901. [CrossRef] [PubMed]

20. Herebian, D.; Lopez, L.C.; Distelmaier, F. Bypassing human $\mathrm{CoQ}_{10}$ deficiency. Mol. Genet. Metab. 2018, 123, 289-291. [CrossRef] 
21. Wang, Y.; Oxer, D.; Hekimi, S. Mitochondrial function and lifespan of mice with controlled ubiquinone biosynthesis. Nat. Commun. 2015, 6, 6393. [CrossRef] [PubMed]

22. Hidalgo-Gutierrez, A.; Barriocanal-Casado, E.; Bakkali, M.; Diaz-Casado, M.E.; Sanchez-Maldonado, L.; Romero, M.; Sayed, R.K.; Prehn, C.; Escames, G.; Duarte, J.; et al. beta-RA reduces DMQ/CoQ ratio and rescues the encephalopathic phenotype in Coq9 (R239X) mice. EMBO Mol. Med. 2019, 11, e9466. [CrossRef]

23. Wang, Y.; Smith, C.; Parboosingh, J.S.; Khan, A.; Innes, M.; Hekimi, S. Pathogenicity of two COQ7 mutations and responses to 2,4-dihydroxybenzoate bypass treatment. J. Cell. Mol. Med. 2017, 21, 2329-2343. [CrossRef] [PubMed]

24. Widmeier, E.; Airik, M.; Hugo, H.; Schapiro, D.; Wedel, J.; Ghosh, C.C.; Nakayama, M.; Schneider, R.; Awad, A.M.; Nag, A.; et al. Treatment with 2,4-Dihydroxybenzoic Acid Prevents FSGS Progression and Renal Fibrosis in Podocyte-Specific Coq6 Knockout Mice. J. Am. Soc. Nephrol. 2019, 30, 393-405. [CrossRef]

25. Widmeier, E.; Yu, S.; Nag, A.; Chung, Y.W.; Nakayama, M.; Hugo, H.; Buerger, F.; Schapiro, D.; Choi, W.-I.; Kim, J.-W.; et al. ADCK4 deficiency destabilizes the coenzyme $\mathrm{Q}$ complex, which is rescued by 2,4-dihydroxybenzoic acid treatment. J. Am. Soc.Nephrol. 2020, 31, 1191-1211. [CrossRef]

26. Liu, F.; Lossl, P.; Rabbitts, B.M.; Balaban, R.S.; Heck, A.J.R. The interactome of intact mitochondria by cross-linking mass spectrometry provides evidence for coexisting respiratory supercomplexes. Mol. Cell. Proteom. 2018, 17, 216-232. [CrossRef]

27. Cox, J.; Mann, M. MaxQuant enables high peptide identification rates, individualized p.p.b.-range mass accuracies and proteomewide protein quantification. Nat. Biotechnol. 2008, 26, 1367-1372. [CrossRef] [PubMed]

28. Raimundo, N.; Vanharanta, S.; Aaltonen, L.A.; Hovatta, I.; Suomalainen, A. Downregulation of SRF-FOS-JUNB pathway in fumarate hydratase deficiency and in uterine leiomyomas. Oncogene 2009, 28, 1261-1273. [CrossRef]

29. Barriocanal-Casado, E.; Hidalgo-Gutierrez, A.; Raimundo, N.; Gonzalez-Garcia, P.; Acuna-Castroviejo, D.; Escames, G.; Lopez, L.C. Rapamycin administration is not a valid therapeutic strategy for every case of mitochondrial disease. EBioMedicine 2019, 42, 511-523. [CrossRef]

30. Rogers, G.W.; Brand, M.D.; Petrosyan, S.; Ashok, D.; Elorza, A.A.; Ferrick, D.A.; Murphy, A.N. High throughput microplate respiratory measurements using minimal quantities of isolated mitochondria. PLoS ONE 2011, 6, e21746. [CrossRef]

31. Salminen, A.; Kaarniranta, K.; Kauppinen, A. Regulation of longevity by FGF21: Interaction between energy metabolism and stress responses. Ageing Res. Rev. 2017, 37, 79-93. [CrossRef] [PubMed]

32. Carriere, A.; Fernandez, Y.; Rigoulet, M.; Penicaud, L.; Casteilla, L. Inhibition of preadipocyte proliferation by mitochondrial reactive oxygen species. FEBS Lett. 2003, 550, 163-167. [CrossRef]

33. Wagner, G.; Lindroos-Christensen, J.; Einwallner, E.; Husa, J.; Zapf, T.C.; Lipp, K.; Rauscher, S.; Groger, M.; Spittler, A.; Loewe, R.; et al. HO-1 inhibits preadipocyte proliferation and differentiation at the onset of obesity via ROS dependent activation of Akt2. Sci. Rep. 2017, 7, 40881. [CrossRef] [PubMed]

34. Cheng, M.; Olivier, P.; Diehl, J.A.; Fero, M.; Roussel, M.F.; Roberts, J.M.; Sherr, C.J. The p21(Cip1) and p27(Kip1) CDK 'inhibitors' are essential activators of cyclin D-dependent kinases in murine fibroblasts. EMBO J. 1999, 18, 1571-1583. [CrossRef] [PubMed]

35. Ferguson, B.S.; Nam, H.; Morrison, R.F. Curcumin Inhibits 3T3-L1 Preadipocyte Proliferation by Mechanisms Involving Posttranscriptional p27 Regulation. Biochem. Biophys. Rep. 2016, 5, 16-21. [CrossRef]

36. Lehrke, M.; Lazar, M.A. The many faces of PPARgamma. Cell 2005, 123, 993-999. [CrossRef]

37. Schoonjans, K.; Staels, B.; Auwerx, J. The peroxisome proliferator activated receptors (PPARS) and their effects on lipid metabolism and adipocyte differentiation. Biochim. Biophys. Acta 1996, 1302, 93-109. [CrossRef]

38. Pierrel, F. Impact of Chemical Analogs of 4-Hydroxybenzoic Acid on Coenzyme Q Biosynthesis: From Inhibition to Bypass of Coenzyme Q Deficiency. Front. Physiol. 2017, 8, 436. [CrossRef] [PubMed]

39. Liu, D.; Lin, Y.; Kang, T.; Huang, B.; Xu, W.; Garcia-Barrio, M.; Olatinwo, M.; Matthews, R.; Chen, Y.E.; Thompson, W.E. Mitochondrial dysfunction and adipogenic reduction by prohibitin silencing in 3T3-L1 cells. PLoS ONE 2012, 7, e34315. [CrossRef]

40. Hawley, S.A.; Fullerton, M.D.; Ross, F.A.; Schertzer, J.D.; Chevtzoff, C.; Walker, K.J.; Peggie, M.W.; Zibrova, D.; Green, K.A.; Mustard, K.J.; et al. The ancient drug salicylate directly activates AMP-activated protein kinase. Science 2012, 336, 918-922. [CrossRef]

41. Jung, Y.; Park, J.; Kim, H.L.; Youn, D.H.; Kang, J.; Lim, S.; Jeong, M.Y.; Sethi, G.; Park, S.J.; Ahn, K.S.; et al. Vanillic acid attenuates testosterone-induced benign prostatic hyperplasia in rats and inhibits proliferation of prostatic epithelial cells. Oncotarget 2017, 8, 87194-87208. [CrossRef] [PubMed]

42. Garcia, D.; Shaw, R.J. AMPK: Mechanisms of Cellular Energy Sensing and Restoration of Metabolic Balance. Mol. Cell 2017, 66, 789-800. [CrossRef]

43. Herzig, S.; Shaw, R.J. AMPK: Guardian of metabolism and mitochondrial homeostasis. Nat. Rev. Mol. Cell Biol. 2018, 19, 121-135. [CrossRef] [PubMed]

44. Yang, Y.Y.; Vasta, V.; Hahn, S.; Gangoiti, J.A.; Opheim, E.; Sedensky, M.M.; Morgan, P.G. The role of DMQ(9) in the long-lived mutant clk-1. Mech. Ageing Dev. 2011, 132, 331-339. [CrossRef]

45. Freyer, C.; Stranneheim, H.; Naess, K.; Mourier, A.; Felser, A.; Maffezzini, C.; Lesko, N.; Bruhn, H.; Engvall, M.; Wibom, R.; et al. Rescue of primary ubiquinone deficiency due to a novel COQ7 defect using 2,4-dihydroxybensoic acid. J. Med. Genet. 2015, 52, 779-783. [CrossRef] 
46. Gonzalez-Garcia, P.; Hidalgo-Gutierrez, A.; Mascaraque, C.; Barriocanal-Casado, E.; Bakkali, M.; Ziosi, M.; Abdihankyzy, U.B.; Sanchez-Hernandez, S.; Escames, G.; Prokisch, H.; et al. Coenzyme $\mathrm{Q}_{10}$ modulates sulfide metabolism and links the mitochondrial respiratory chain to pathways associated to one carbon metabolism. Hum. Mol. Genet. 2020, 29, 3296-3311. [CrossRef] [PubMed]

47. Aranaz, P.; Navarro-Herrera, D.; Zabala, M.; Migueliz, I.; Romo-Hualde, A.; Lopez-Yoldi, M.; Martinez, J.A.; Vizmanos, J.L.; Milagro, F.I.; Gonzalez-Navarro, C.J. Phenolic Compounds Inhibit 3T3-L1 Adipogenesis Depending on the Stage of Differentiation and Their Binding Affinity to PPARgamma. Molecules 2019, 24, 1045. [CrossRef]

48. Hsu, C.L.; Yen, G.C. Effects of flavonoids and phenolic acids on the inhibition of adipogenesis in 3T3-L1 adipocytes. J. Agric. Food Chem. 2007, 55, 8404-8410. [CrossRef] [PubMed]

49. Xie, L.X.; Williams, K.J.; He, C.H.; Weng, E.; Khong, S.; Rose, T.E.; Kwon, O.; Bensinger, S.J.; Marbois, B.N.; Clarke, C.F. Resveratrol and para-coumarate serve as ring precursors for coenzyme Q biosynthesis. J. Lipid Res. 2015, 56, 909-919. [CrossRef] [PubMed]

50. Rosen, E.D.; Spiegelman, B.M. Molecular regulation of adipogenesis. Annu. Rev. Cell Dev. Biol. 2000, 16, 145-171. [CrossRef]

51. Jo, J.; Gavrilova, O.; Pack, S.; Jou, W.; Mullen, S.; Sumner, A.E.; Cushman, S.W.; Periwal, V. Hypertrophy and/or Hyperplasia: Dynamics of Adipose Tissue Growth. PLoS Comput. Biol. 2009, 5, e1000324. [CrossRef] [PubMed]

52. Tchoukalova, Y.D.; Votruba, S.B.; Tchkonia, T.; Giorgadze, N.; Kirkland, J.L.; Jensen, M.D. Regional differences in cellular mechanisms of adipose tissue gain with overfeeding. Proc. Natl. Acad. Sci. USA 2010, 107, 18226-18231. [CrossRef] [PubMed]

53. Landgraf, K.; Rockstroh, D.; Wagner, I.V.; Weise, S.; Tauscher, R.; Schwartze, J.T.; Loffler, D.; Buhligen, U.; Wojan, M.; Till, H.; et al. Evidence of early alterations in adipose tissue biology and function and its association with obesity-related inflammation and insulin resistance in children. Diabetes 2015, 64, 1249-1261. [CrossRef] [PubMed]

54. Gerich, J.E.; Meyer, C.; Woerle, H.J.; Stumvoll, M. Renal gluconeogenesis: Its importance in human glucose homeostasis. Diabetes Care 2001, 24, 382-391. [CrossRef]

55. Legouis, D.; Faivre, A.; Cippa, P.E.; de Seigneux, S. Renal gluconeogenesis: An underestimated role of the kidney in systemic glucose metabolism. Nephrol. Dial. Transplant. 2020, gfaa302. [CrossRef] [PubMed]

56. Liu, X.; Cooper, D.E.; Cluntun, A.A.; Warmoes, M.O.; Zhao, S.; Reid, M.A.; Liu, J.; Lund, P.J.; Lopes, M.; Garcia, B.A.; et al. Acetate Production from Glucose and Coupling to Mitochondrial Metabolism in Mammals. Cell 2018, 175, 502-513. [CrossRef]

57. Shi, L.; Tu, B.P. Acetyl-CoA and the regulation of metabolism: Mechanisms and consequences. Curr. Opin. Cell Biol. 2015, 33, 125-131. [CrossRef] [PubMed]

58. Huang, Z.; Zhang, M.; Plec, A.A.; Estill, S.J.; Cai, L.; Repa, J.J.; McKnight, S.L.; Tu, B.P. ACSS2 promotes systemic fat storage and utilization through selective regulation of genes involved in lipid metabolism. Proc. Natl. Acad. Sci. USA 2018, 115, E9499-E9506. [CrossRef] [PubMed]

59. Fletcher, J.A.; Deja, S.; Satapati, S.; Fu, X.; Burgess, S.C.; Browning, J.D. Impaired ketogenesis and increased acetyl-CoA oxidation promote hyperglycemia in human fatty liver. JCI Insight 2019, 4, e127737. [CrossRef] [PubMed]

60. Mariappan, M.M.; Prasad, S.; D’Silva, K.; Cedillo, E.; Sataranatarajan, K.; Barnes, J.L.; Choudhury, G.G.; Kasinath, B.S. Activation of glycogen synthase kinase 3beta ameliorates diabetes-induced kidney injury. J. Biol. Chem. 2014, 289, 35363-35375. [CrossRef] 